\title{
WestVirginiaUniversity
}

THE RESEARCH REPOSITORY @ WVU

Graduate Theses, Dissertations, and Problem Reports

2018

\section{Ergot Alkaloid Synthetic Capacity of Penicillium camemberti}

Samantha J. Fabian

Follow this and additional works at: https://researchrepository.wvu.edu/etd

\section{Recommended Citation}

Fabian, Samantha J., "Ergot Alkaloid Synthetic Capacity of Penicillium camemberti" (2018). Graduate Theses, Dissertations, and Problem Reports. 5562.

https://researchrepository.wvu.edu/etd/5562

This Thesis is protected by copyright and/or related rights. It has been brought to you by the The Research Repository @ WVU with permission from the rights-holder(s). You are free to use this Thesis in any way that is permitted by the copyright and related rights legislation that applies to your use. For other uses you must obtain permission from the rights-holder(s) directly, unless additional rights are indicated by a Creative Commons license in the record and/ or on the work itself. This Thesis has been accepted for inclusion in WVU Graduate Theses, Dissertations, and Problem Reports collection by an authorized administrator of The Research Repository @ WVU. For more information, please contact researchrepository@mail.wvu.edu. 


\title{
Ergot alkaloid synthetic capacity of Penicillium camemberti
}

\author{
Samantha J. Fabian
}

Thesis submitted to the Davis College of Agriculture, Natural Resources and Design at West Virginia University

In partial fulfillment of the requirements for the degree of

Master of Science in Genetics and Developmental Biology

\author{
Daniel Panaccione, Ph.D., Chair \\ Matthew Kasson, Ph.D. \\ Nikola Kovinich, Ph.D.
}

Department of Genetics and Development Biology

Morgantown, West Virginia

2018

Keywords: ergot alkaloids, biosynthetic pathways, rugulovasines, Penicillium camemberti, Neosartorya fumigata, aldehyde dehydrogenase, camembert cheese Copyright 2018 Samantha Fabian 


\section{Abstract \\ Ergot alkaloid synthetic capacity of Penicillium camemberti}

Samantha Fabian

Penicillium camemberti plays a major role in the ripening process of brie and camembert type cheeses. Investigation of the recently sequenced $P$. camemberti genome revealed the presence of a cluster of five genes previously shown to be required for ergot alkaloid synthesis in other fungi. Clustered with the five ergot alkaloid synthesis genes (aka eas genes) were two additional genes with that had the apparent capacity to encode enzymes involved in secondary metabolism. We analyzed samples of brie and camembert cheeses as well as cultures of $P$. camemberti grown under different conditions and were not able to detect any known ergot alkaloids, indicating the $P$. camemberti eas genes were either not expressed or encoded non-functional enzymes. We used a heterologous expression strategy to investigate the theoretical biosynthetic capacity of $P$. camemberti. Based on studies with the related ergot alkaloid-producing fungus Neosartorya fumigata (syn. Aspergillus fumigatus), the five known eas genes found clustered in the $P$. camemberti genome should give the fungus the capacity to produce the ergot alkaloid chanoclavine-I aldehyde. We used a chanoclavine-I aldehyde-accumulating mutant of $N$. fumigata as a recipient strain in which to express the two uncharacterized $P$. camemberti eas cluster genes (named eas $H$ and eas $Q$ ) to create a functioning facsimile of the $P$. camemberti cluster. Expression of easH and eas $Q$ in the chanoclavine-I accumulating $N$. fumigata resulted in the accumulation of a pair of compounds of $m / z 269.1$ in positive mode LC-MS. Since this $m / z$ is consistent with the mass of the isomeric pair of [rugulovasine $A / B+H$ ], we analyzed a culture of the related rugulovasine producer Penicillium biforme and found the same isomeric pair of analytes. Fragmentation of the analytes yielded fragments typical of those resulting from fragmentation of rugulovasine $A / B$. The deduced activities of the products of eas $H$ and eas $Q$ catalyze theoretical reactions that provide a reasonable pathway from the precursor chanoclavine-I aldehyde to the products rugulovasine A/B. When individually studied, the chanoclavine-I aldehydeaccumulating mutant of $N$. fumigata transformed with the $P$. camemberti eas $Q$ gene yielded a ratio of analytes at $m / z 271.1$ vs. $m / z 255.1$ that support the theorized mechanisms of eas $H$ and eas $Q$ to produce rugulovasines. The $P$. biforme genome contains a homologous eas cluster with only 12 mutations relative to that of $P$. camemberti. Eleven of the 12 mutations were investigated via complementation studies of the mutated genes ( $d$ maW, eas $C$, eas $E$ ) using knockout strains of $N$. fumigata. The data indicate that $P$. camemberti has the genes to produce the ergot alkaloid rugulovasine $A / B$ but that during domestication isolates that failed to produce alkaloids were selected for. 


\section{Table of Contents}

Abstract

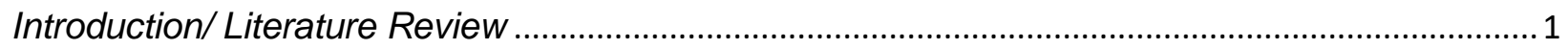

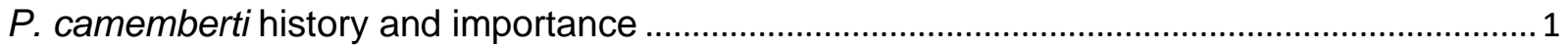

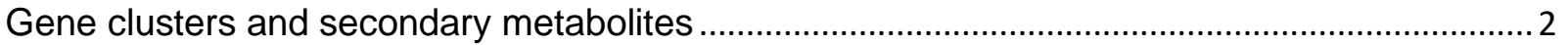

Examples of secondary metabolites produced by Penicillium species........................................ 3

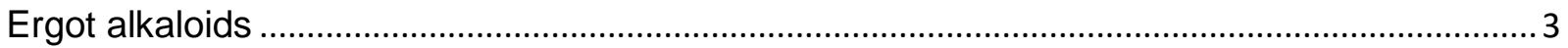

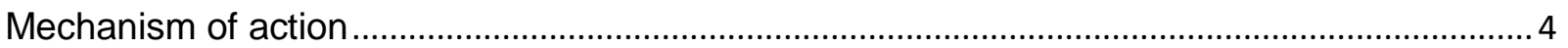

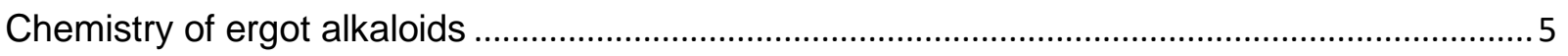

Genes of the ergot alkaloid synthesis cluster ............................................................................ 5

Susceptible to evolution adaptability and mutability of Penicillium species ............................... 6

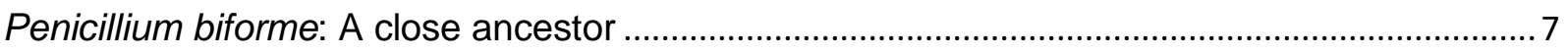

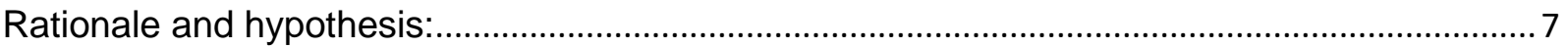

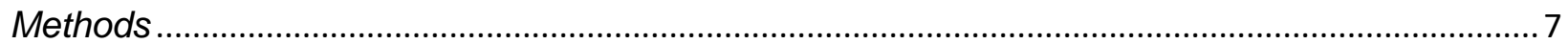

Characterization of $P$. camemberti and $P$. biforme ergot alkaloid gene clusters........................ 7

Liquid chromatography mass spectrometry (LC-MS) analysis ................................................. 8

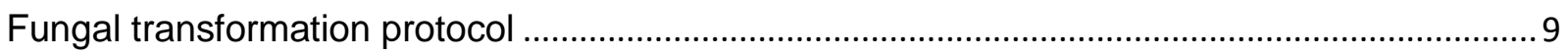

Preparation of gene constructs for fungal transformation...................................................... 10

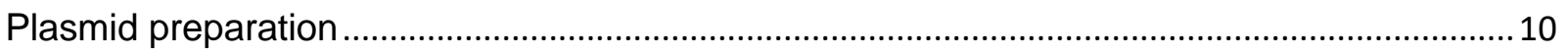

Expression of of easQ/easH Fusion PCR product in N. fumigata ............................................11

Observation of the individual function of $P$. camemberti eas $H$ and eas $Q$................................12

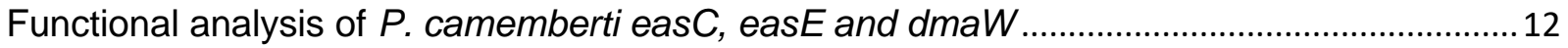

Extraction of messenger RNA and preparation of cDNA ......................................................... 13

Analysis of different Penicillium spp. isolates and cheese prepared with $P$. camemberti or $P$.

biforme for ergot alkaloids.................................................................................................... 13

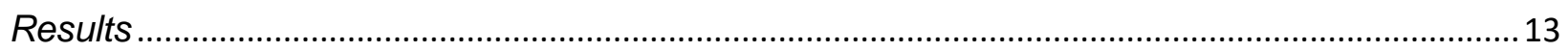

Penicillium camemberti has an ergot alkaloid synthesis (eas) gene cluster with a unique

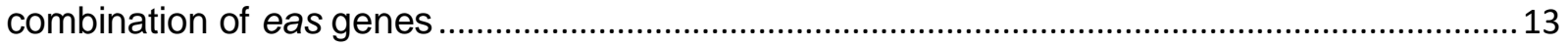

Penicillium camemberti alleles of easH and eas $Q$ contribute to ergot alkaloid synthesis ........14

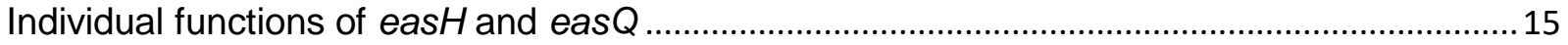

Investigation of the lack of accumulation of ergot alkaloids in P. camemberti strain NRRL 874

Analysis of potential ergot alkaloid accumulation in cheese ................................................. 18

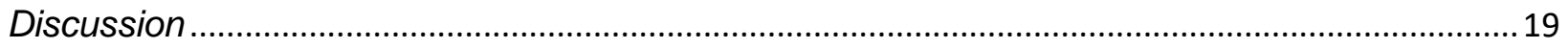




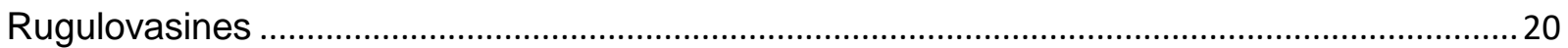

Proposed mechanism of rugulovasine biosynthesis ..................................................................2 21

Ancestral species of P.camemberti are rugulovasine producers.............................................24

Lack of ergot alkaloid production in P. camemberti................................................................... 25

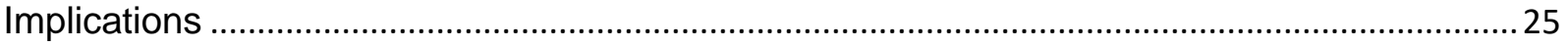

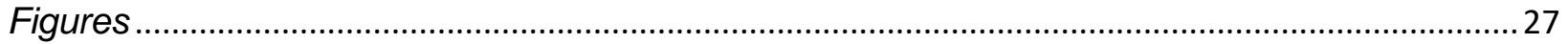

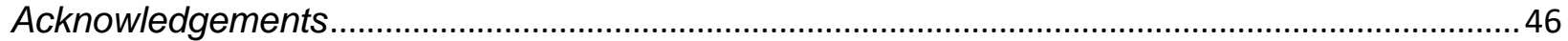

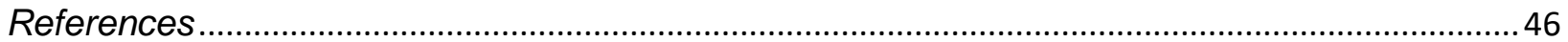




\section{Introduction/ Literature Review}

\section{$P$. camemberti history and importance}

Camembert type cheeses were thought to be first made in 1791 in the village of Camembert, near Normandy, France by Marie Harel (Spinnler and Gripon, 2004). While Camembert is a popular choice for U.S. consumers today, it holds historical significance in French culture. The WWI French troops were famously issued the cheese in their military rations and thus it gained popularity. The process of this making cheese is highly dependent on $P$. camemberti. Without the fungus, the cheese would not have the characteristic flavor and texture, as the mold plays a crucial part in the ripening process.

During the initial stages of the cheese making process, the milk is inoculated with P. camemberti as well as bacterial cultures and renin. As the cheese matures, the fungus colonizes the entire outside surface area giving the cheese its characteristic white felt rind. Perhaps the biggest contribution $P$. camemberti has to the ripening process is its ability to oxidize lactate, as the lactate is the main food source for the fungus (McSweeny, 2004). As a result of the lactate metabolism, gradients are established that help with the transport of other compounds from the middle of the cheese to the surface rind. $P$. camemberti oxidizes lactate to $\mathrm{CO}_{2}$ and $\mathrm{O}_{2}$ and over time results in increasing the $\mathrm{pH}$ of the rind of the cheese (McSweeny, 2004). This deacidification leads to the creation of a $\mathrm{pH}$ gradient from the cheese center to the rind which allows lactate to move to the rind surface, where it is oxidized by $P$. camemberti. The increase in $\mathrm{pH}$ on the rind also creates a calcium phosphate gradient, which allows migration of calcium and phosphate from the center to the cheese surface. The proteolysis by $P$. camemberti on the rind creates an excess of ammonia, which diffuses 
into the cheese giving it its distinct odor. The initial oxidation of the lactate of the cheese is key in its production as it continues until all of the available lactate is metabolized.

The degradation of protein in camembert cheeses is very complex and involves many different microorganisms including lactic acid bacteria. However, P. camemberti contributes to the proteolysis of the cheese by making aspartyl and metalloproteinases, acid carboxypeptidase and an alkaline aminopeptidase (McSweeny, 2004). The aspartyl proteinases acts on $\alpha$-casein, while the acid carboxypeptidases work on $\beta$-casein, hydrolyzing the Lys97-Va98I, Lys99-Glu100, and Lys29-lle30 bonds (McSweeney \& Fox, 2004). In the process of lipolysis, the milk itself contains lipolytic agents such as lipoprotein lipase. The renin coagulant and the starter microorganisms can also provide lipases that can metabolize the lipids present. $P$. camemberti has been found to oxidize linoleic and linolenic acids with lipoxygenases and hydroperoxide-lipases. It is capable of producing 9-, 10-, and 13-hydroperoxy acids from polyunsaturated fatty acid oxidation (Spinnler and Gripon, 2004). However, there is minimal lipolysis occurring in the cheese as the high lipid concentrations give the cheese its creamy texture.

\section{Gene clusters and secondary metabolites}

Fungi have interesting clusters of genes that encode the ability to produce secondary metabolites, or chemical compounds that can be beneficial in some way for the fungi. These clusters can code for catabolic pathways, activated to allow the fungus to survive under low nutrient/competitive environments by using low molecular weight nutrients as energy source (Keller and Hohn, 1997). They also code for enzymes that act as catalysts of biosynthetic pathways producing secondary metabolites (Keller and Hohn, 1997). While there are many, some common examples include penicillin and ergot alkaloids. The secondary metabolites can be beneficial or sometimes harmful to 
plants, humans and animals. Secondary metabolite production is controlled by the activation/deactivation of the transcription of certain genes that are found in a cluster (Brakhage and Schroeckh, 2011). These gene clusters are unique to the chemical compound being produced but can be found in an array of different fungi. On another note, the discovery of these gene cluster does not mean the fungus is producing the metabolite, but rather that it has the potential to produce it.

\section{Examples of secondary metabolites produced by Penicillium species}

Penicillium species are producers of many secondary metabolites such as the well-known antibiotic penicillin. P. camemberti has been known to produce acetaldehyde, benzaldehyde, 3-methylbutanal and 1-octen-3-ol to inhibit the bacteria Listeria monocytogenes and Salmonella typhimurium (Larsen and Knochel, 1997). It is believed that the production of these chemicals is beneficial to $P$. camemberti as it reduces the competition of these potentially pathogenic gram negative/gram positive bacteria by inhibiting their growth. Additionally, $P$. roqueforti the fungus associated with the production of blue/roquefort cheese has been known to make antibiotics such as penicillin, as well as mycophenolic acid and patulin (Neilsen et al., 2006). P. roqueforti is also known for making ergot alkaloids festuclavine, isofumigaclavine $A$ and isofumigaclavine B (Neilsen et al., 2006). Festuclavine is also made by $P$. crustosum, $P$. palitans and P. oxalicum (Kozlovsky, 1999) Therefore, it is not uncommon for Penicillium species to produce ergot alkaloids.

\section{Ergot alkaloids}

Ergot alkaloids are most famously produced by the fungus Claviceps purpurea and also are produced by a large range of other fungi including Epichloë spp. and Neosartorya fumigata (Panaccione and Coyle, 2005). They can also be produced by 
certain Penicillium spp. that were previously discussed (Kozlovsky, 1999). Ergot alkaloids can be viewed as beneficial or harmful depending on the dose and context. Ergot alkaloid derivatives can be used directly or often are modified to serve as pharmaceuticals as well as illegal drugs, such as lysergic acid diethylamide or LSD. The most popular legal ergot alkaloid-derived drugs produced are for treating migraines, depression, prolactin disorders, gynecological issues, dementia and Parkinson's (Hulvova et at., 2013). The known fungal producers of these alkaloids are grown under optimal alkaloid production settings and then the alkaloids are extracted for use. However, ergot alkaloids can be harmful if consumed without any chemical modification or in uncontrolled doses. Ergot alkaloid poisoning, or ergotism, can cause a wide range of symptoms from hallucinations, gangrene, burning skin, neurological diseases and even death. Ergotism can occur in both humans and animals. Today, the incidence of ergotism is uncommon due to modern farming practices, but high levels of ergot alkaloids can still be found in the grasses of less advanced farming systems. Historically, ergotism was a widespread problem that was referred to as St. Anthony's Fire that swept across Europe and the early American colonies. The largest epidemic of ergotism occurred in 994 AD in Aquitaine, France where around 40,000 people died as a result (VanDongen and DeGroot, 1995).

\section{Mechanism of action}

The above-mentioned benefits and dangers of ergot alkaloids can be explained by the mechanism in which they affect the body. Because they have a similar chemical structure to the neurotransmitters dopamine, serotonin and norepinephrine, ergot alkaloids interact with the receptors for those neurotransmitters (Tudzynski et al., 2001). Figure 1 highlights the similarity among an alkaloid and three neurotransmitters. 
However, the way the alkaloids interact with the neurotransmitters depend on the alkaloids structure and the particular sub-type of receptor. In some cases, ergot alkaloids act as agonists, whereas in other cases they are antagonists. Adding different chemical substituents to $\mathrm{C}-8$ of the ergoline ring gives the alkaloid different affinities toward the different neuroreceptors (Schardl et al., 2006). Simple peptide ergot alkaloids have a high affinity for adrenergic receptors and thus are responsible for the vasoconstrictive effects. However, the clavines have a high affinity for serotonin receptors and therefore responsible for the anti-serotoninergic action. Some ergot alkaloids can also have an effect on prolactin release and are therefore manipulated for pharmaceutical use for conditions like galactorrhea (Schardl et al., 2006).

\section{Chemistry of ergot alkaloids}

Chemically, the backbone of the alkaloids consists of 3,4-substituted indole derivatives with a tetracyclic ergoline ring structure (Tudzynski et al., 2001). There are three group classes of ergot alkaloids: clavines, lysergic acid amides, and ergopeptines based on their level of complexity and additional groups (Panaccione, 2005). The alkaloids are synthesized from the amino acid tryptophan and then metabolized into various pathway end products via enzymatic reactions. The enzymes are coded for by ergot alkaloid synthesis or Eas genes.

\section{Genes of the ergot alkaloid synthesis cluster}

The publicly available genome of $P$. camemberti features five ergot alkaloid synthesis (eas) genes in its genome: $d m a W$, eas $C$, eas $E$, eas $F$, and easD. In $N$. fumigata, these genes code for the enzymes that catalyze synthesis of DMAPP and tryptophan into chanoclavine-I aldehyde (Figure 2; Figure 3). More specifically, the dmaW gene encodes for the enzyme dimethylallyltryptophan synthase which converts 
tryptophan and DMAPP to dimethylallyltryptophan or DMAT (Wang et al., 2004; Coyle and Panaccione, 2005). The easF gene is responsible for coding for the enzyme dimethylallyltryptophan-N-methylase which converts DMAT to N-Me-DMAT (Rigbers and $\mathrm{Li}, 2009)$. Genes eas $C$ and easE code for the enzymes catalase and chanoclavinesynthase, respectively (Lorenz et al., 2010; Goetz et al., 2011). While the exact mechanism is unknown, it is known that they work together to form chanoclavine-I (Goetz et al., 2011). The enzyme chanoclavine-I dehydrogenase coded by the easD gene then converts chanoclavine-I to chanoclavine-I aldehyde (Wallwey et al., 2011). This gene cluster and production of chanoclavine-I aldehyde from tryptophan and DMAT is common to most ergot alkaloid producers such as Claviceps/Epichloë and Neosartorya/Penicillium. At this point, the synthesis of the specific ergot alkaloids produced by the different species is catalyzed by different enzymes in lineage-specific branches.

\section{Susceptible to evolution adaptability and mutability of Penicillium species}

Multiple lines of evidence have led to the idea that Penicillium species are readily susceptible to evolutionary processes. One such example of evolutionally adaptation is the concept of horizontal gene transfer between different species of Penicillium. $P$. camemberti and $P$. roqueforti are known to undergo these gene transfers frequently with each other. While these two species of Penicillium are both primarily grown on dairy substrates and are used to produce cheese, phylogenetically they are not closely related (Cheeseman et al., 2014). However, they were found to undergo the same horizontal gene transfers of two genes that give the fungi fitness and competitive advantages in a cheese environment (Cheeseman et al., 2014). 


\section{Penicillium biforme: A close ancestor}

While $P$. camemberti is a characteristically white mold found exclusively in cheese products, it is a descendent of Penicillium biforme and Penicillium fuscoglaucum which are blue/gray type molds (Ropars et al., 2015). Because of its close relation to $P$. camemberti, P. biforme was also studied as part of this thesis project. P. biforme naturally occurs in cheese substrates but has been found to be a contaminant in other dairy-based foods and juices as well. P. bifome is a known producer of the ergot alkaloid rugulovasine (Dorner et al., 1980). Like other known ergot alkaloid producers, my preliminary investigation of its publicly available genome indicated it has the first five ergot alkaloid synthesis genes along with two additional genes, easH and easQ (Figure 3). Thus, the ability of $P$. camemberti to produce ergot alkaloids was studied due to its close relation to $P$. biforme and its importance in the production of camembert cheese.

\section{Rationale and hypothesis:}

Due to the previously studied activities of the five ergot alkaloid synthesis genes found in $P$. camemberti, the ability of this fungus to produce ergot alkaloids was researched. Considering that other Penicillium species are capable of producing alkaloids and rapidly evolving, it is reasonable to hypothesize that $P$. camemberti has the capacity to produce ergot alkaloids. With $P$. biforme phylogenetically being a recent ancestor to $P$. camemberti, it could be that during domestication mutations caused this gene cluster to no longer function in $P$. camemberti.

\section{Methods}

Characterization of $\boldsymbol{P}$. camemberti and $\boldsymbol{P}$. biforme ergot alkaloid gene clusters The ergot alkaloid gene cluster in $P$. camemberti was found by comparing individual eas genes from $N$. fumigata to the NCBI database. Contigs containing $P$. 
camemberti and $P$. biforme eas gene clusters were downloaded and additional genes were annotated by BlastX searching individual, contiguous 5-kb fragments.

\section{HPLC analysis}

Fungi were cultured on malt extract agar (6g malt extract, 1.8 maltose, $6 \mathrm{~g}$ dextrose, $1.2 \mathrm{~g}$ yeast extract per liter of distilled water) for 7 to 10 days, and samples were prepared for HPLC analysis by cutting a $1 \mathrm{~cm}$ by $1 \mathrm{~cm}$ piece of fungus-colonized medium and adding it to $400 \mu \mathrm{L}$ of HPLC grade methanol. Samples were rotated endover-end (15 rpm) for 35 minutes and centrifuged at 13,000 rpm for 10 minutes. One hundred $\mu \mathrm{L}$ of supernatant was placed into an HPLC sample vial and $20 \mu \mathrm{L}$ was analyzed for ergot alkaloids on reverse phase liquid chromatography using a C18 column and the protocol outlined in Panaccione et al. (2012). Analytes were monitored by fluorescence with excitation at $272 \mathrm{~nm}$ and the emission $372 \mathrm{~nm}$. The area under the peaks were measured and converted into $\mathrm{ng} / \mathrm{mL}$ using a standard curve generated from prior HPLC data.

\section{Liquid chromatography mass spectrometry (LC-MS) analysis}

Samples were prepared for LC-MS by using $5 \mathrm{~mL}$ of $100 \%$ methanol to remove all spores and hyphae from the malt extract agar cultures grown for 7-21 days. Two $\mathrm{mL}$ of the harvested spore suspension was centrifuged at $13,000 \mathrm{rpm}$ for 10 minutes. The supernatant was collected and concentrated to $100 \mu \mathrm{L}$ in a speedvac. Ten $\mu \mathrm{L}$ of the extract was then analyzed with a Thermo Fisher LCQ LC-MS according to methods described by Ryan et al. (2013) except the gradient program initiated with $86 \%$ mobile phase A ( 5 parts acetonitrile +95 parts $0.1 \%$ formic acid) and $14 \%$ mobile phase $B$ ( $75 \%$ acetonitrile arts acetonitrile +95 parts $0.1 \%$ formic acid) and increased linearly to $100 \%$ mobile phase B over 20 minutes. Flow was maintained at $100 \%$ B for 5 min, 
before initial conditions were restored. Flow rate was $200 \mu \mathrm{L} / \mathrm{min}$. The peaks in the chromatograms of interest were measured using the LC-Qual browser and analyzed for the observation of conversion ratios.

\section{Fungal transformation protocol}

Cultures for preparing protoplasts for transformation were grown as follows. A 2$\mathrm{cm} \times 2-\mathrm{cm}$ sample of fungus-colonized malt extract agar of various strains of $N$. fumigata was used as inoculum to start cultures in $50 \mathrm{~mL}$ of malt extract broth. Cultures were incubated overnight at $37^{\circ} \mathrm{C}, 80 \mathrm{rpm}$. To prepare protoplasts, the broth was replaced with $15 \mathrm{~mL} 0.7 \mathrm{M} \mathrm{NaCl}$ that included $40 \mathrm{mg}$ lysing enzyme (Sigma-Aldrich, St. Louis, MO) and $1 \mathrm{~g}$ VinoTaste Pro (Gusmer Enterprises Inc., Mountainside, NJ). The enzyme-mycelium mixture was then incubated for 2 hours at $37^{\circ} \mathrm{C}$ and $80 \mathrm{rpm}$. The mixture was filtered through a miracloth (EMD Chemicals, Gibbstown, NJ) lined funnel in order to separate the protoplasts from the hyphae and other debris. The protoplasts were pelleted by centrifuging for three minutes at $3000 \mathrm{rpm}$. The supernatant was decanted, and then the protoplasts were resuspended with $10 \mathrm{~mL} 0.7 \mathrm{M} \mathrm{NaCl}$ and then re-pelleted. The process was then repeated but with resuspension in $5 \mathrm{~mL} \mathrm{STC} \mathrm{(1} \mathrm{M}$ Sorbitol, OmM Tris $\mathrm{pH} 7.4,10 \mathrm{~m} 6 \mathrm{M} \mathrm{CaCl}_{2}$ ). The protoplasts were then resuspended in a final volume of STC that allowed for a protoplast concentration of $5 \times 10^{6}$ protoplasts in $100 \mu \mathrm{L}$ STC. Two volumes of $37.5 \%$ PEG 8000 and one volume of PEG amendments $(1.8 \mathrm{M} \mathrm{KCl}, 150 \mathrm{mM} \mathrm{CaCl}, 150 \mathrm{mM}$ Tris $\mathrm{pH}=7.4$ ) were mixed together in order to prepare a polyethylene glycol (PEG) solution. A quarter of the final protoplast volume was calculated, and then the prepared PEG was added in that amount. Ten $\mu \mathrm{L}$ of plasmid DNA or PCR product was added to the $125 \mu \mathrm{L}$ of the final protoplast mixture, which was incubated on ice for 30 minutes. One $\mathrm{mL}$ of the PEG solution was added to 
the cells and then the mixture was incubated at room temperature for 20 minutes. The solution was then divided among three Petri dishes and mixed with $15 \mathrm{~mL}$ molten TM102 media, which corresponds to M102 medium as defined by Rykard et al. (1982) but containing $1 \mathrm{M}$ sucrose. After the agar had solidified, $15 \mathrm{~mL}$ of molten TM102 mixed with $800 \mu \mathrm{g} / \mathrm{mL}$ phleomycin (InvivoGen, San Diego, CA) was added on top of solidified layer. The plates were incubated at $37^{\circ} \mathrm{C}$ for three days.

\section{Preparation of gene constructs for fungal transformation}

A typical PCR reaction was comprised of $11 \mu \mathrm{L}$ distilled/deionized water, $5 \mu \mathrm{L} 5 \mathrm{x}$ Phsuion HF buffer (100 mM KCl, 20 mM Tris-HCl pH 7.4, 1.5 mM MgCl2; Thermo Scientific, Waltham, MA), $4 \mu \mathrm{L} 1.25 \mathrm{mM}$ dNTPs, $1.25 \mu \mathrm{L} 0.5 \mathrm{mM}$ forward primer, $1.25 \mu \mathrm{L}$ $0.5 \mathrm{mM}$ reverse primer, $2 \mu \mathrm{L}$ of template DNA and $0.5 \mu \mathrm{L}$ of Phusion high-fidelity polymerase (Thermo Scientific).The reactions underwent the same general cycle, with an initial denaturation at $98^{\circ} \mathrm{C}$ for $30 \mathrm{~s}$, followed by 35 cycles of $98^{\circ} \mathrm{C}(15 \mathrm{~s})$, annealing temperature (as defined by primer pair in Table 1) $(15 \mathrm{~s})$, and $72^{\circ} \mathrm{C}$ for and extension time as defined in Table 1, followed by a final extension at $72^{\circ} \mathrm{C}$ for $60 \mathrm{~s}$. The primers, annealing temperatures, and extension times are included in Table 1. The PCR products were cleaned using the Zymogen DNA Clean \& Concentrator kit (Zymo Research Corp., Irvine, CA). The cleaned products observed via gel electrophoresis in $0.8 \%$ agarose.

\section{Plasmid preparation}

Various restriction enzyme sites were included in the primers used to PCR amplify different gene fragments. The PCR products with restriction enzyme sites were cleaned using the Zymogen DNA Clean \& Concentrator kit (Zymo Research Corp., Irvine, CA) and then digested with the appropriate restriction endonuclease for 90 minutes at $37^{\circ} \mathrm{C}$. The following solution mix was used for all digestions: $6 \mu \mathrm{L}$ of cleaned 
PCR products with restriction sites, $10 \mu \mathrm{L}$ distilled water, $2 \mu \mathrm{L}$ of CutSmart buffer (New England BioLabs, Ipswich, MA) and $1 \mu \mathrm{L}$ each of the corresponding restriction enzymes associated with the specific gene products. A previously prepared pBCPhleo PCR product was also digested under the same conditions with the same set of restriction enzymes used for the individual gene PCR product. The digested products were cleaned using the Zymogen DNA Clean \& Concentrator kit. The cleaned digests were loaded on a $0.8 \%$ agarose gel and the intensities of the products were recorded. A ligation reaction was created based on the observed intensities of the digested fragments, with $8 \mu \mathrm{L}$ of the mixture being comprised of a ratio of the amplified gene digest and the digested pBCphleo; along with $1 \mu \mathrm{L}$ of $10 \mathrm{x}$ ligation buffer and $1 \mu \mathrm{L}$ of ligase (New England BioLabs, Ipswich, MA). The solution was incubated at $16^{\circ} \mathrm{C}$ overnight. The ligation was then transformed into a Novagen NovaBlue ${ }^{\mathrm{TM}}$ Competent $E$ .coli cells (EMD Biosciences Inc, Darmstadt, Germany) and grown on LB + chloramphenicol $(50 \mu \mathrm{g} / \mathrm{mL})$ agar. Resulting colonies were isolated and grown in $2 \mathrm{~mL}$ of $\mathrm{LB}+$ chloramphenicol broth and incubated at $37^{\circ} \mathrm{C}$ overnight. The cells were pelleted and the plasmids were purified using the Zyppy ${ }^{\mathrm{TM}}$ Plasmid Miniprep kit (Zymo Research Corp., Irvine, CA).

\section{Expression of of easQ/easH Fusion PCR product in N. fumigata}

The eas $H$ and eas $Q$ genes of $P$. camemberti were individually PCR amplified using primer sets 13 and 14 (Table 1). The cleaned PCR products were then then attached to a $N$. fumigata easA/eas $G$ bidirectional promoter via fusion PCR. The previously generated eas $H$, eas $Q$ and a previously generated $N$. fumigata promoter PCR products were used as template DNA and the primer set 15 (Table 1). The 4145bp fusion PCR product along with a previously created pBCphleo linear plasmid were 
co-transformed in an equal molar concentration into a previously created chanoclavine-I aldehyde accumulating eas $A$ ko strain of $N$. fumigata (Coyle et al., 2010).

Transformants were analyzed by HPLC with fluorescence detection and LC-MS.

\section{Observation of the individual function of $P$. camemberti eas $H$ and eas $Q$}

$P$. camemberti eas $H$ and eas $Q$ gene fragments with restriction enzyme sites were PCR amplified using primers 11 and 12, respectively (Table 1). The easH fragment contained restriction enzyme sites for Notl and BamHI, while the eas $\mathrm{PCR}$ product contained sites for Notl and Spel. The PCR products were digested with their corresponding restriction enzyme set, cleaned, and then ligated with $\mathrm{pBCphleo.} \mathrm{The}$ resulting plasmid was used for fungal transformation into the $N$. fumigata eas $A$ knockout strain (Coyle et al., 2010). The successful transformants were analyzed by HPLC with fluorescence detection along with LC-MS.

\section{Functional analysis of $P$. camemberti eas $C$, easE and dmaW}

The functionality of $P$. camemberti eas $C$, eas $E$ and $d m a W$ was tested by using those genes in attempted complementation of previously characterized N. fumigata knockout mutants. The P. camemberti gene fragments were PCR amplified using primer sets 1, 2 and 3 (Table 1) that included restriction enzyme sites. The easC fragment contained sites for BamHI and EcoRI, easE featured sites for Notl and Spel, and dmaW had restriction enzyme sites for Notl and BamHI. The cleaned PCR products were digested with the indicated restriction enzyme set, cleaned and then ligated with similarly-digested pBCphleo. The resulting plasmids were used for fungal transformation into previously made eas $C$, easE and dmaW knockout strains of $N$. fumigata (Goetz et al., 2011; Coyle \& Panaccione, 2005). The transformants were plated on malt extract agar plates and analyzed by HPLC with fluorescent detection. 


\section{Extraction of messenger RNA and preparation of CDNA}

Cultures of $P$. camemberti NRRL 874 were grown as surface cultures on malt extract broth for three days at room temperature. A $100 \mathrm{mg}$ sample of the fungal mat was then frozen with liquid nitrogen and ground into a powder with a mortar and pestle. RNA was then extracted by following the instructions of the Qiagen RNeasy Plant kit (Qiagen Company, Hilden, Germany). cDNA was obtained by reverse transcribing the mRNA with SuperScript IV reverse transcriptase (Thermo Scientific, Waltham, MA). The cDNA was then used as template for primer sets $4,5,6,7,8,9$ and 10 (Table 1). PCR products were analyzed via gel electrophoresis.

Analysis of different Penicillium spp. isolates and cheese prepared with $\boldsymbol{P}$. camemberti or $\boldsymbol{P}$. biforme for ergot alkaloids

Cultures of $P$. camemberti NRRL 874, NRRL 875, NRRL 66321 and P. biforme

(P. camemberti NRRL strain 885) were grown on malt extract agar at $22^{\circ} \mathrm{C}$ for seven days. Cultures were also analyzed via LC-MS analysis.

Samples of brie and camembert cheese bought commercially and those made in lab were also analyzed using the same HPLC and LC-MS detection methods outlined above. The lab generated cheese samples were made with mesophilic cheese culture (New England Cheesemaking Supply Co., South Deerfield, MA) and P. camemberti NRRL 874 and $P$. biforme NRRL 885 individually as the ripening fungi. Curds were allowed to mature for eight weeks.

\section{Results}

Penicillium camemberti has an ergot alkaloid synthesis (eas) gene cluster with a unique combination of eas genes

Prior research has established that the genes $d m a W$, eas $F$, eas $C$, eas $E$, and eas (Figure 3) encode the enzymes that catalyze the reactions that transform DMAPP 
and tryptophan to chanoclavine-I aldehyde (Figure 2). Genomes of other fungi were investigated for contigs that contain the eas genes through sequence queries. The search revealed that $P$. camemberti contains an eas cluster containing homologs of $d m a W$, eas $F$, eas $C$, easE, and easD (Figure 3;Table 2). This same observation has recently been noted by Martin et al. (2017). Further analysis of the $P$. camemberti contig that contained the eas gene cluster revealed a copy of the gene easH, alleles of which have two very different functions in two different fungi (Havemann et al., 2014; Jakubczyk et al., 2015) and also a copy of a novel gene with undetermined functionality, referred to as eas $Q$ (Figure 3;Table 2). The presence of this combination of genes indicated that $P$. camemberti has the genetic potential to produce chanoclavine-I aldehyde, with the possibility that the products of eas $H$ and eas $Q$ genes modify chanoclavine-I aldehyde into a more complex ergot alkaloid.

\section{Penicillium camemberti alleles of eas $H$ and eas $Q$ contribute to ergot alkaloid synthesis}

Roles in ergot alkaloid biosynthesis for $P$. camemberti genes easH and eas $Q$ were derived via transformation studies. The eas $H$ and eas $Q$ genes of $P$. camemberti strain NRRL 874 were individually PCR amplified and then attached to a N. fumigata easA/eas G bidirectional promoter via fusion PCR. The easH/eas $Q$ fusion PCR product was co-transformed along with pBC-Phleo into a chanoclavine aldehyde accumulating eas $A$ ko strain of $N$. fumigata. Eight fungal transformant colonies grew on $400-\mu \mathrm{g} / \mathrm{mL}$ phleomycin plates and were then analyzed by HPLC with fluorescence detection to observe alkaloid accumulation. While chanoclavine aldehyde was detected, no novel or additional alkaloids were observed in the HPLC analysis. DNA was extracted from the transformants and studied via PCR to investigate the presence of the construct (Figure 4). A transformant that contained easH and eas $Q$ was further analyzed by LC-MS to 
compare its metabolite profile with that of the recipient eas $A$ ko strain of $N$. fumigata (Figures 5 and 6). The transformed fungal strain was found to produce chanoclavine-I (Figure $5 \mathrm{C}$ ) and a pair of analytes with $\mathrm{m} / \mathrm{z}$ values of 269.1288 (Figure 6). A pair of compounds with the same molecular ion and retention times was produced by Penicillium biforme (Figure 6), a close relative and proposed ancestor to $P$. camemberti but not by the chanoclavine aldehyde-accumulating eas $A$ ko strain of $N$. fumigata used as a recipient in this experiment (Figure 5). Prior research has established that $P$. biforme produces of the isomeric pair of ergot alkaloids called rugulovasine $A$ and rugulovasine $B$, the $[\mathrm{M}+\mathrm{H}]^{+}$for each of which has a calculated $\mathrm{m} / \mathrm{z}$ of 269.1285 . Further comparison of $P$. biforme and the easH/eas $Q$-transformed eas $A$ ko strain of $N$. fumigata via fragmentation analysis revealed that the two produced identical fragments, the $\mathrm{m} / \mathrm{z}$ values of which matched with the fragments produced upon fragmentation of rugulovasine (De Medeiros et al., 2015) (Figure 6). The data indicate that that the products of eas $H$ and eas $Q$ act on chanoclavine aldehyde to produce rugulovasines $A$ and $\mathrm{B}$.

\section{Individual functions of eas $H$ and eas $Q$}

While together eas $H$ and eas $Q$ were observed to produce rugulovasines from chanoclavine-I aldehyde, the individual functions of the products of these genes were also explored. P. camemberti easH gene under the control of the $N$. fumigata eas $A$ promoter was transformed into the chanoclavine-I aldehyde-accumulating eas $A$ ko strain of $N$. fumigata. Ten transformants containing the easH expression construct grew on media containing $400 \mu \mathrm{g} / \mathrm{mL}$ phleomycin, indicating that those cultures had taken up the phleomycin resistance-conferring construct. PCR analysis of genomic DNA template demonstrated that the transformant contained the introduced easH gene (Figure 7A). 
RT-PCR analysis of cDNA template demonstrated that the easH mRNA was transcribed in the transformant (Figure 8A), indicating that the gene was being expressed. Sequence analysis and prior research indicates that both EasH and EasQ may be oxidases. Thus it is likely that they may be adding an oxygen to chanoclavine-I aldehyde. This addition would result in the $\mathrm{m} / \mathrm{z}$ value observed for chanoclavine-I aldehyde increasing from 255 to 271 . Therefore, special attention was paid in LC/MS analyses for appearance or increase in analytes with $\mathrm{m} / \mathrm{z}$ of 271 . The transformed strain was analyzed for accumulation of ergot alkaloids by HPLC with fluorescence detection and by LC-MS, but no novel peaks or ratios were observed as compared to the profile of the $N$. fumigata easA knockout. Eas $Q$ was studied in the same manner, by transforming the chanoclavine-I aldehyde accumulating easA ko strain of $N$. fumigata with the $P$. camemberti eas $Q$ gene linked with the $N$. fumigata easA promoter. PCR and RT-PCR analyses indicated the gene was present and transcribed (Figure 7B; Figure 8B). HPLC with fluorescence detection did not reveal the presence of any novel metabolites when only a single gene was expressed. However, when analyzed on LCMS it was observed there was a large peak at $m / z$ in the eas $Q$ transformant. This $m / z$ 271 peak was also observed in the $N$. fumigata eas $A$ knockout and the eas $H$ transformant, but in very small quantities. Thus, it was hypothesized that the $m / z 271$ product may be the oxidation product of the $m / z 255$ analyte (chanoclavine-l aldehyde) and that the ratios of these anayltes may differ between strains. The areas under the EIC peaks were then measured and analyzed using ANOVA. It was found that the ratios were significantly different based on the measured strain ( $p=0.0017)$. A Tukey's multiple comparison test showed that the $N$. fumigata easA with the eas $Q$ gene had a much higher $m / z 271$ to $m / z 255$ ratio than the $N$. fumigata eas $A$ knockout strain $(p=0.002)$ or 
the eas $H$ transformned N.fumigata eas $A$ knockout ( $p=0.007$ ), supporting the hypothesis that EasQ oxidized chanoclavine-I aldehyde to a molecule with $m / z 271$ (Figure 9; Table 3).

\section{Investigation of the lack of accumulation of ergot alkaloids in P. camemberti strain NRRL 874}

Possible reasons for lack of accumulation of rugulovasine in $P$. camemberti include lack of expression of eas genes, misprocessing of eas gene transcripts, or null mutations in individual eas genes. Whether the eas genes of $P$. camemberti were transcriptionally active was investigated in qualitative RT-PCR analyses. Messenger RNA from $d m a W$, eas $F$, eas $C$, easE, eas $D$, eas $H$ and eas $Q$ were present in reverse transcriptase-PCR analyses indicating that those genes are being transcribed in $P$. camemberti strain NRRL 874 when grown in malt extract broth (Figure 10). Additionally, sequencing results proved that the mRNAs were being processed properly, as the cDNA contained open reading frames corresponding to those for functional eas genes from $N$. fumigata.

The possibility that individual eas genes of $P$. camemberti were mutated was investigated by comparing the $P$. camemberti eas gene cluster to the functional eas cluster of $P$. biforme. The contig of $P$. biforme that contains its eas gene cluster was obtained from NCBI GENbank (accession number CBXO010000115.1) and compared to the P. camemberti eas gene cluster (GenBank accession CBVV010000119.1) by Blast analysis. The two eas clusters were nearly identical, with the exception of five differences in the coding regions of eas genes and seven intergenic differences or polymorphisms (Figure 11). Each of the five polymorphisms that occurred within coding sequences resulted in changes in amino acids in four different enzymes (Figure 11C). 
Two amino acid changes occurred in EasE, one in EasC, one in DmaW, and one in EasQ.

In order to test functionality of the $P$. camemberti eas genes, three of the four genes that contained SNPs relative to the established functional homologs in P. biforme were transformed into previously constructed $N$. fumigata knockout strains; the function of EasQ was evident from its co-expression with EasH in N. fumigata strain easA ko. Transformation with $P$. camemberti $d m a W$ and easE complemented the respective $N$. fumigata mutants. Transformed strains that contained the dmaW or easE constructs each accumulated fumigaclavine $\mathrm{C}$, indicating that the $P$. camemberti allele restored the N. fumigata ergot alkaloid pathway (Figure 12; Figure 7C-D). Attempts to complement an eas $C$ knockout mutant of $N$. fumigata (Goetz et al., 2011) did not result in a strain that expressed easC, thus the function of the EasC enzyme could not be assessed.

\section{Analysis of potential ergot alkaloid accumulation in cheese}

Four different wheels of Camembert cheese were cultured and ripened with $P$. biforme NRRL strain 885 and P. camemberti NRRL strain 874 for eight weeks (Figure 13). Samples were analyzed by LC-MS along with a sample of $P$. biforme grown on malt extract agar for comparison. Rugulovasine was not detected in any camembert cheese sample. Samples of commercial cheese ripened with $P$. camemberti also were investigated and found to be free of rugulovasine and chanoclavine-I. 


\section{Discussion}

My data illustrates that $P$. camemberti previously had the genetic capacity to produce ergot alkaloids such as chanoclavine-I and rugulovasines A and B. My research also has identified a new ergot alkaloid biosynthesis gene (easQ), provided evidence for a novel functionality of an allele of the gene eas $\mathrm{H}$, and indicated a biosynthetic pathway for the rugulovasine class of ergot alkaloids. The transformation of easH and eas $Q$ into the chanoclavine-I aldehyde-accumulating eas $A$ knockout strain of $N$. fumigata induced the fungus to produce the alkaloids rugulovasines $\mathrm{A}$ and $\mathrm{B}$. The biochemical activity and sequence in which eas $\mathrm{H}$ and eas $\mathrm{Q}$ functioned were also studied. Typically, the eas genes present in N. fumigata control the reactions to turn tryptophan and dimethylallylpyrophosphate to chanoclavine-I aldehyde and then to festuclavine and fumigaclavine A, B, and C (Figure 2) (Robinson and Panaccione, 2015). While it is clear from the expression studies in $N$. fumigata that the easH and eas $Q$ genes of $P$. camemberti are functional, $P$. camemberti does not produce ergot alkaloids in culture nor were the alkaloids detected in any cheese samples obtained or created. To explain this lack of ergot alkaloids in $P$. camemberti in light of the genetic data, we looked at evolutionary data, taking into account the closely related rugulovasine-producing strains of Penicillium spp. Differences in the eas gene clusters between $P$. camemberti and $P$. biforme were studied through complementation and mRNA expression studies to investigate a possible explanation. It was found that $P$. camemberti encodes functional easE and dmaW genes but further investigation of the eas $C$ gene is needed to fully understand if all the genes in the ergot alkaloid synthesis gene cluster are functional. 


\section{Rugulovasines}

Structurally, rugulovasines are classified as indole alkaloids in the ergot family that contain a spirocyclic butyrolactone subunit (Zhang et al., 2013). Rugulovasines are unique as they occur as two racemic isomers, $A$ and $B$, that are capable of being interconverted by heating in polar solvents (Meurant, 2012). Ergot alkaloids are great chemical structures to undergo biohalogenation as they contain nitrogen in their chemical structure (Gribble, 2008). Thus, it there are also naturally-occurring chlorinated and brominated forms of rugulovasine (De Medeiros et al., 2015).

While the health effects of the rugulovasines are largely understudied, a few studies indicate they may induce negative heath consequences. Previous research showed that ingestion of rugulovasines by day-old poultry caused acute toxicity effects (Dorner et al., 1980). In fact, this toxicity was used as a bioassay to purify the rugulovasines. It has also been reported that the rugulovasines caused decreased blood pressure when administered to cats (Meurant, 2012). Our LC-MS data indicate that $P$. biforme and the easH/eas $Q$-transformed eas $A$ ko strain of $N$. fumigata are capable of producing both rugulovasine A and B (Figure 6). This is evident as the fragmentation spectra for both rugulovasine $A$ and $B$ match the fragmentation spectra of rugulovasines from previous studies (De Medeiros et al., 2015). However, the chlorinated and brominated forms of rugulovasine were not detected when analyzed on LC-MS based on the absence of analytes of the predicted masses established in analyses by De Medeiros et al. (2015). It is also pertinent to note that while rugulovasines were detected in large quantities in our LC-MS data, they were not detected on the HPLC with fluorescence detection (monitoring at excitation/emission wavelengths of $272 \mathrm{~nm} / 372 \mathrm{~nm}$ or $310 \mathrm{~nm} / 410 \mathrm{~nm}$, respectively). Future steps may be 
to monitor different combinations of excitation and emission wavelengths in order for the rugulovasines to fluoresce for detection on the HPLC. It is also possible that the particular structure of these compounds prevents or quenches fluorescence.

\section{Proposed mechanism of rugulovasine biosynthesis}

We hypothesize that EasQ, predicted by sequence analysis to be an aldehyde dehydrogenase, oxidizes chanoclavine-I aldehyde to the corresponding carboxylic acid (Figure 14). As the name indicates, an aldehyde dehydrogenase is capable of acting on aldehydes, oxidizing the aldehyde to a carboxylic acid. The aldehyde dehydrogenase family of enzymes are NADP-dependent that share the basic structural and functional attributes that allow them to catalyze the oxidation of a number of different aliphatic and aromatic aldehydes (Lindahl, 1992). Evidence that the $P$. camemberti eas $Q$ gene is similar yet different from the other forms of aldehyde dehydrogenases can be observed from the phylogenetic and sequence match data (Figure 14B). In fact, a close homolog of eas $Q$ with two introns in identical position and phase is found in the $P$. camemberti genome and has close homologs in several other members of the Trichocomaceae, including $N$. fumigata. The data favor that eas $Q$ acts as the nomenclature indicates, turning chanoclavine-I aldehyde into chanoclavine-I acid (Figure 15). Analysis of the transformed chanoclavine-I aldehyde accumulating eas $A$ knockout strain of $N$. fumigata with the easQ gene on LC-MS supports this proposed mechanism as copious amounts of an analyte with the mass of [chanoclavine-l acid $+\mathrm{H}]^{+}(\mathrm{m} / \mathrm{z} 271)$ was detected (Figure 9). Whereas small quantities of this same metabolite were observed in the N. fumigata eas $A$ knockout strain, the ratio of chanoclavine-I (resumed substrate) to the $m / z 271$ analyte (presumed product) increased significantly upon expression of easQ. These results supported the hypothesis that EasQ may be acting on chanoclavine-I aldehyde 
and converting it to the corresponding carboxylic acid. The amounts of the $m / z 271$ analyte compared to chanoclavine-I were also compared to the levels of these analytes found in the eas $A$ knockout strain of $N$. fumigata with the easH gene as well as the chanoclavine-I aldehyde accumulating eas $A$ knockout strain of $N$. fumigata (Figure 9). While there were trace amounts of the presumed chanoclavine-I acid found in the chanoclavine-I aldehyde accumulating eas $A$ knockout strain of $N$. fumigata, the increase in the analyte of this mass in the easQ-transformed strain as well as the ratios between the aldehyde and the proposed acid are indicative of the actions of EasQ (Figure 15). Furthermore, Blastp search has indicated that there is a distant eas $Q$ homologue present in N. fumigata as well as in $P$. camemberti. The other $P$. camemberti homologue, which is $58 \%$ identical in amino acid sequence to the product of the eas $Q$ gene used in this study, may be the parent gene from which eas $Q$ was neofunctionalized (Figure $14 \mathrm{~A}, \mathrm{~B}$ ). Thus, the product of this gene in $N$. fumigata may be responsible for the small background quantities of the analyte with the mass of chanoclavine-I acid in N. fumigata. However, the data strongly favors that the $P$. camemberti EasQ is capable of converting chanoclavine-I aldehyde to chanoclavine-I acid (Figure 9).

EasH, a predicted dioxygenase, would oxidize the aromatic carbon customarily labeled as carbon 10 in chanoclavine-I aldehyde or perhaps that same carbon in the corresponding carboxylic acid, chanoclavine-I acid. Dehydration of the 10-hydroxylated chanoclavine-I acid would result in the formation of rugulovasine A (Figure 15). The literature supports that this proposed mechanism is possible but novel, as the product of no other form of the easH gene has acted on this proposed substrate. Jakubczyk et al. (2015) proposed three mechanisms by which EasH of the fungus Aspergillus japonicus 
might oxidize the very same carbon in a slightly different ergot alkaloid precursor to result in formation of cycloclavine. That study outlined three potential mechanisms that may be encoded for by the easH gene (Figure 16). The first two outlined mechanisms propose that EasH may be abstractring a hydride ion (Figure 16A), or abstracting a hydrogen ion from its substrate (Figure 16B). Figure $16 \mathrm{C}$ shows that EasH may be hydroxylating or halogenating its substrate. Hydroxylation is the mechanism that is consistent with our hypothesis for $P$. camemberti EasH, as it would explain hydroxylating the chanoclavine-I acid produced from the actions of eas $Q$

A study with another allele of easH from Claviceps purpurea stated that easH has the ability to code for enzymes that can hydroxlate amino acids that are in the first position of ergopeptines. The study also found that the product of that particular allele of easH was capable of cyclolizying the ergopeptine classes that are naturally occurring (Havemann et al., 2014). Figure 13C and D illustrates the phylogenetic relationships between the easH alleles from these fungi as well as those other fungi that share a similar easH gene with $P$. camemberti. The phylogenetic clustering of $P$. camemberti eas $\mathrm{H}$ with those involved in cycloclavine biosynthesis support the hypothesis that they have similar activities on a similar substrate.

If EasH were to act on chanoclavine-I aldehyde (as opposed to it acid derivative described above), we propose that the intermediate would essentially be chanoclavine-I aldehyde with an additional oxygen at carbon 10, thus making its $\mathrm{m} / \mathrm{z}$ around 271 . While the easH gene alone was successfully transformed into the chanoclavine-I aldehyde-accumulating eas $A$ knockout strain of $N$. fumigata (Figure $6 \mathrm{~B}$ ), when analyzed on LC-MS there were no notable traces of this proposed intermediate. It is possible that Eas $Q$ needs to act on chanoclavine-I aldehyde first before EasH can undertake its 
oxidation mechanisms (Figure 15). It may also be that intermediate is unstable in this form and therefore does not stay in solution long enough to be detected. The fact that the production of rugulovasine was detected when both eas $H$ and eas $Q$ were expressed supports the notion that they work together in catalyzing chanoclavine-I aldehyde into rugulovasine.

\section{Ancestral species of P.camemberti are rugulovasine producers}

Phylogenetic analysis shows that $P$. biforme, $P$. fuscoglaucum and $P$. commune are perhaps the ancestral strains of $P$. camemberti (Ropars et al., 2015; Polonelli et al., 1987). P. biforme, $P$. fuscoglaucum and $P$. commune are known as common contaminants of cheese and other food products. The close phylogenetic relationship between $P$. biforme, $P$. fuscoglaucum and $P$. camemberti was confirmed by using 17 different microsatellite markers (Giraud et al., 2009). P. biforme and $P$. commune are known for producing rugulovasines (Kozlovsky,1999).

There are two chemotypes of $P$. commune, with Chemotype I being associated as a producer of cyclopenoxoic acid and rugulovasine and chemotype II producing fumigoclavines. P. camemberti is thought to have descended from P. commune chemotype I or the one that is known for producing rugulovasines (Frisvad and Filtenborg, 1989). This hypothesis is supported by data from Polonelli et al. (1987) who analyzed what appeared to be a $P$. camemberti mutant that produced the same alkaloids as $P$. commune. It was determined that this "mutant" was actually in a $P$. commune, thus $P$. commune must be the ancestor of $P$. camemberti (Polonelli et al., 1987). All of these phylogenic lineages favor the notion that the ancestor to $P$. 
camemberti had the genetic capacity to produce rugulovasine but at some point in the domestication of the commercial strain the fungus lost that ability.

\section{Lack of ergot alkaloid production in $P$. camemberti}

While the data suggest that the products of the $P$. camemberti easH and eas $Q$ genes act on chanoclavine-I aldehyde to produce rugulovasines, ergot alkaloids were not detected in any strain of $P$. camemberti. Interestingly enough, $P$. camemberti does transcribe all of the eas genes in the ergot alkaloid synthesis gene cluster under the cultural conditions commonly used in our analyses (Figure 9), which involved culturing the fungus in malt extract medium without agitation at ambient temperature. Sequence data collected on these transcripts indicated proper processing of mRNAs, eliminating that step as a reason for the lack of ergot alkaloids in $P$. camemberti. P. biforme shares a similar ergot alkaloid gene cluster with $P$. camemberti with the exception of a few nucleotide differences (Figure 11). Because there were minor differences between the $P$. camemberti eas $C$, eas $E$ and $d m a W$ genes in comparison to the $P$. biforme eas genes, these genes were selected for complementation studies. The P. camemberti $d m a W$ and easE genes were found to be fully functional, as they were able to be transformed into the $N$. fumigata the respective knockout strain and restore the fungus's ability to produce festuclavine $\mathrm{C}$ (Figure 12). However, attempts to express the $P$. camemberti eas $C$ failed to result in accumulation of eas $C$ mRNA. One potential reason for this observation is that expression of $P$. camemberti eas $C$ in $N$. fumigata may require placing the coding sequences of the gene under the control of an N. fumigata promoter.

\section{Implications}

The collected data has shown an ancestral capacity of $P$. camemberti to produce ergot alkaloids. The data suggested potential mechanisms of the novel $P$. camemberti 
eas $Q$ gene and the novel allele of easH and the role they play in the production of rugulovasines. Moreover, while it may be reassuring to know that domesticated strains of $P$. camemberti used for the production of camembert-type cheeses did not produce any detectable ergot alkaloids, some Penicillium strain associated with dairy products may have the ability to produce rugulovasines (Polonelli et al., 1987). While there is little known about how rugulovasines may affect human health, the literature does indicate that it is a compound that may have detrimental heath impacts if prolonged exposure persists (Dorner et al., 1980; Meurant, 2012).

It is possible that $P$. biforme may produce rugulovasines as a means of defense of resources and that $P$. camemberti does not need this defense as it is only found on cheese products which have a defined microflora and are cultivated hygienically. Another theory is that historically the rugulovasines may have made consumers of the cheese sick, therefore strains of $P$. camemberti that were unable to produce these alkaloids were selected. It is possible that there may be more to this observation and therefore it should be further studied. Future studies to try to explain this phenomenon would include sequencing and comparing the eas gene cluster of $P$. fuscoglaucum and P. commune to try to pinpoint where this divergence may have occurred. Also, it is pertinent to note that while $P$. biforme produces rugulovasines in culture, no alkaloids were detected when $P$. biforme was grown on cheese substrates. 
Figures
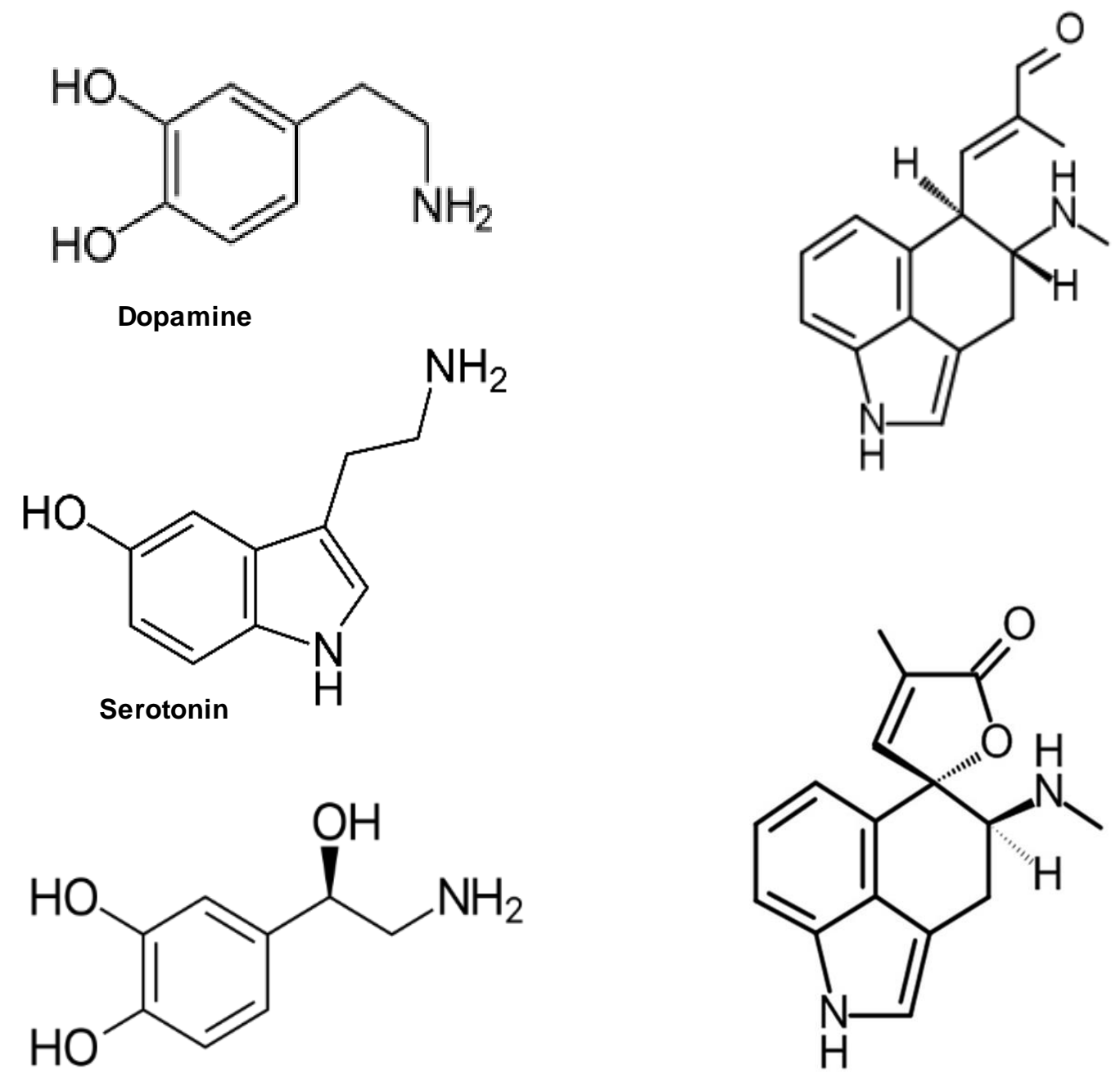

Norepinephrine

Figure 1: Chemical structures of neurotransmitters dopamine, serotonin and norepinephrine on the left. These neurotransmitters interact with neuroreceptors to elicit a neuronal response in the body. Chemical structures of ergot alkaloids chanoclavine-I aldehyde and rugulovasine A are pictured on the right. Ergot alkaloids have a similar chemical backbone as the neurotransmitters, thus they can interact with the neuroreceptors as well. 

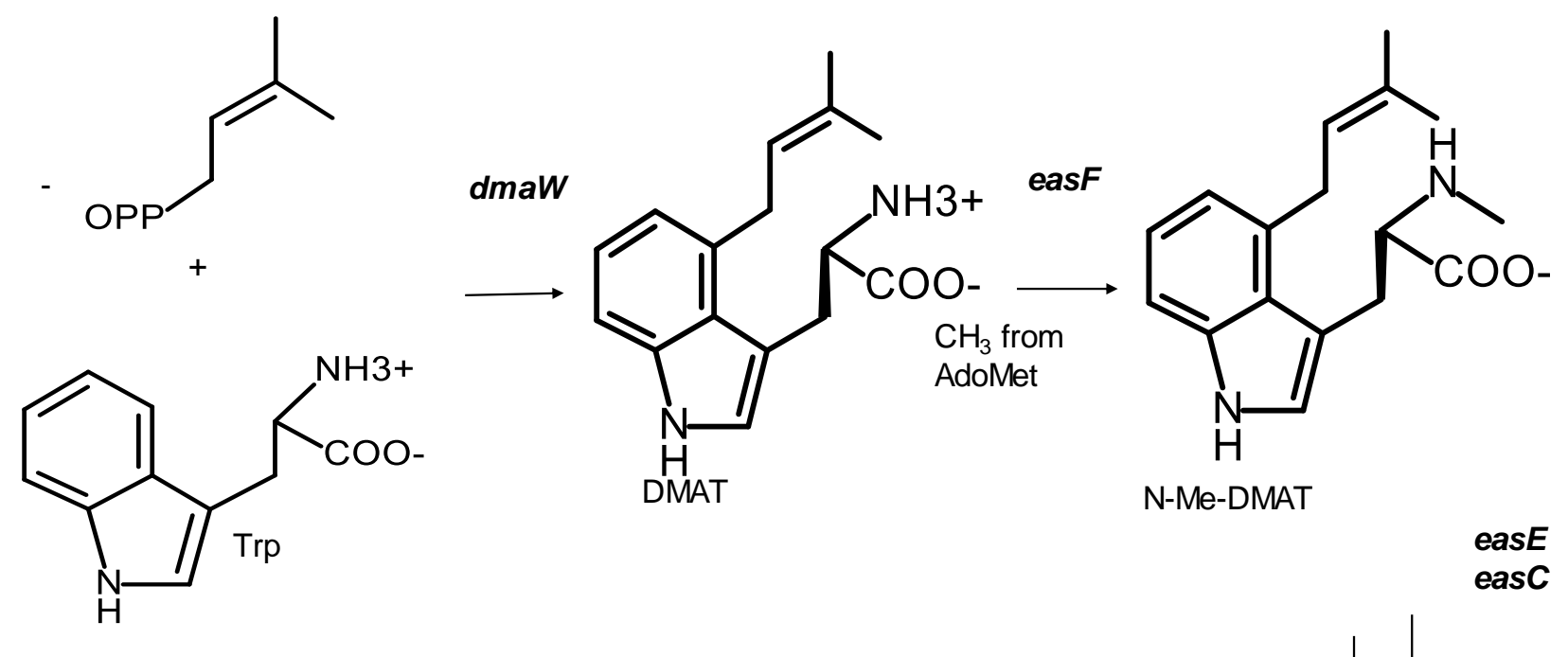

$\mathrm{CH}_{3}$ from

AdoMet

$$
\text { N-Me-DMAT }
$$

easE

easC<smiles>C1CCCCC1</smiles><smiles>CN[C@H]1Cc2c[nH]c3cccc(c23)[C@H]1/C=C(\C)C=O</smiles>

chanoclavine---aldehyde<smiles>CN[C@H]1Cc2c[nH]c3cccc(c23)[C@H]1/C=C(\C)CO</smiles>

chanoclavine-I

Figure 2: Series of reactions catalyzed by the eas genes converting tryptophan and N-methyl DMAT to chanoclavine-I aldehyde. This pathway is common to most ergot alkaloid producers, with chanoclavine-I aldehyde acting as the branching point into more specialized alkaloids 

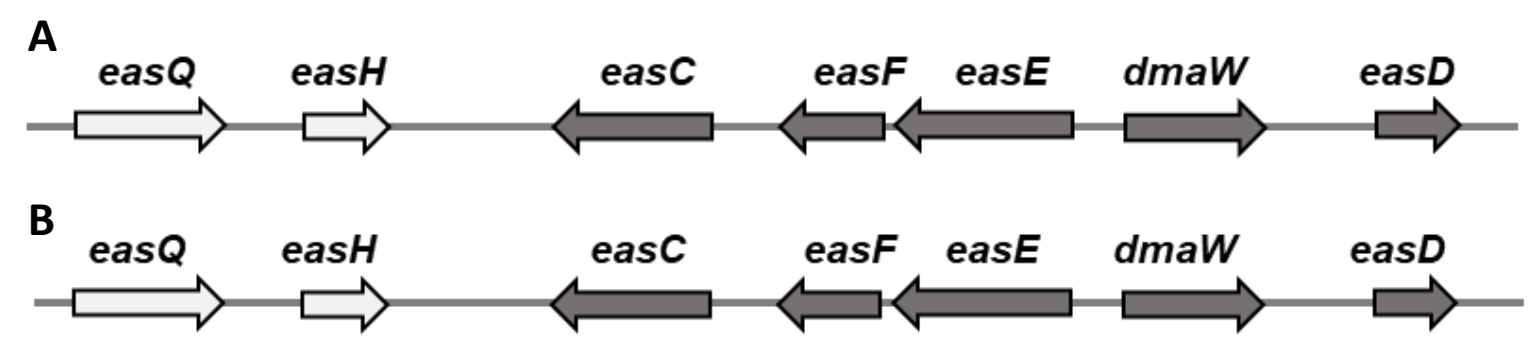

\section{C}

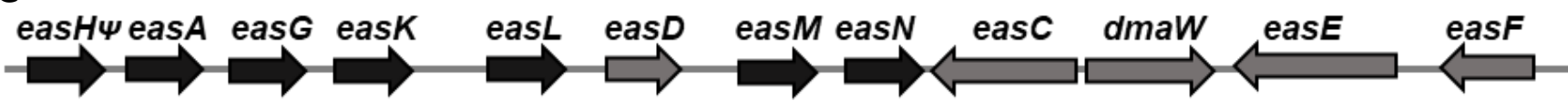

Figure 3: A: The ergot alkaloid synthesis gene cluster from $P$. camemberti. Genes eas $C$, easF, easE, dmaW, and easD are also found in $N$. fumigata. The combination of easH and eas $Q$ are novel to $P$. camemberti and $P$. biforme. B: Ergot alkaloid gene cluster found in $P$. biforme. C: gene cluster found in $N$. fumigata. While the eas gene cluster is more extensive in N. fumigata, it shares five of the same genes among $P$. camemberti and $P$. biforme. 
Table 1: Primer combinations, annealing temperature, and extension time for the various PCR reactions.

Primer

Combination
Primer sequences from $5^{\prime}$ to $3^{\prime}$

1 CTCAGAATTCGAGCTGGTCCGCGTTCAGG + CTACGGATTCGTCGCTTGATGGCTGTGATGTAACG

2

CAACGCGGCCGCAAGAGGATAGAGCTTTCAGCTGG + CAGAACTAGTGGTGATTCAACGGAGCCCATGG

3 CATCGGATCCGGCCAACATGACTCCCACGGC + CTACGCGGCCGCGTGTAACTATGGAGGATGACAAGC

4

CGCATCGGGTATTGGTGCCG + CTAGCCACATCCTCGGGCTC

5 GGACTTCCCCAACCATGATCAG+CGAAGGAGGTAGGATGGCCAC

6 GGAGTCATGTTGGCCATCTCGC + GTCCCACTGCCGCTTCAGC

7 GGAATCCGGCACTGGATTGAAC + CTCTCAATCCCGCCGACCC

8 GCCTGGAGCAAGTCAAGTTCTCA + CTGATTCGACGATTCTCTCCACC

10 GTACTTGGTGGATTAGAAGCAATGTGTGAGACATCAATTGATCTGAC + GACTAGGTCAAGCATGACTGGC

11 GTATACTAGTGCAATCCGCAATGAATCTGCAGG+CAGAGCGGCCGCTC TATGTGAAGCATGCGGGAATG

ACCGGATCCGTGCCGTAGTCCTATACTAAG +

12 CCACCGCGGTGGCGGCCGCTATTTCGTCACTTTGGCTTGCATG

GTCAGATCAATTGATGTCTCACACATTGCTTCTAATCCACCAAGTAC * 13 CCACCGCGGTGGCGGCCGCTATTTCGTCACTTTGGCTTGCATG

GTTGGCGCAATTGGAAATCGTCATGGTGCGGAGTGCCTACTC + GGGGATCCACTAGTTCTAGAGCGGCCGCCTCTATGTGAAGCATGCGG 14 GAATGG

15 CCACCGCGGTGGCGGCCGCTATTTCGTCACTTTGGCTTGCATG+ GGGGATCCACTAGTTCTAGAGCGGCCGCCTCTATGTGAAGCATGCGG GAATGG

\begin{tabular}{|c|c|c|c|}
\hline Product & Size (bp) & $\begin{array}{l}\text { Anneling } \\
\text { Temp. } \\
\left({ }^{\circ} \mathrm{C}\right)\end{array}$ & $\begin{array}{l}\text { Ext. } \\
\text { Time (s) }\end{array}$ \\
\hline $\begin{array}{l}\text { easC with BamHI and EcoRI } \\
\text { restriction enzyme sites }\end{array}$ & 3070 & 67 & 90 \\
\hline $\begin{array}{l}\text { easE with Notl and Spel } \\
\text { restriction enzyme sites }\end{array}$ & 3642 & 67 & 90 \\
\hline $\begin{array}{l}\text { ofmaW with } N o t l \text { and } B a m H I \\
\text { restriction enzyme sites }\end{array}$ & 2686 & 67 & 90 \\
\hline easD cDNA gene product & 670 & 62 & 45 \\
\hline dimaW cDNA gene product & 1282 & 62 & 45 \\
\hline easE cDNA gene product & 1570 & 62 & 45 \\
\hline easF cDNA gene product & 853 & 62 & 45 \\
\hline easC cDNA gene product & 1323 & 62 & 45 \\
\hline easH cDNA gene product & 951 & 64 & 45 \\
\hline easQ cDNA gene product & 1659 & 64 & 45 \\
\hline $\begin{array}{l}\text { easQ with Spel and Notl } \\
\text { restriction enzyme sites }\end{array}$ & 2967 & 62 & 90 \\
\hline $\begin{array}{l}\text { easH with BamHI and Notl } \\
\text { restriction enzyme sites }\end{array}$ & 2213 & 62 & 90 \\
\hline N. fumigata promotor + easH & 2228 & 64 & 90 \\
\hline N. fumigata promotor + eas $Q$ & 2754 & 64 & 90 \\
\hline & 4145 & 64 & 90 \\
\hline
\end{tabular}


Table 2: Ergot alkaloid synthesis genes found in $P$. camemberti and their similarity to genes found in other known alkaloid producing fungi. The $P$. camemberti genome was obtained through NCBI and the individual genes were compared through NCBI Blastx. The function of these genes and percent identity are shown below.

\begin{tabular}{l|l|l|l|l} 
Gene & $\%$ Identity & Species & Function & Accession number \\
\hline easQ & $97 \%$ & Aspergillus flavus & aldehyde dehydrogenase & XP_002376976.1 \\
\hline easH & $99 \%$ & Byssochlamys spectabilis & Phytanoyl-CoA dioxygenase & GAD93023.1 \\
\hline easC & $86 \%$ & Penicillium roqueforti & Catalase haem-binding site & CDM36675.1 \\
\hline easF & $93 \%$ & Penicillium roqueforti & $\begin{array}{l}\text { SAM-dependent } \\
\text { methyltransferase, EasF- } \\
\text { type }\end{array}$ & CDM36676.1 \\
\hline easE & $94 \%$ & Penicillium roqueforti & $\begin{array}{l}\text { Berberine/berberine-like } \\
\text { CDM36677.1 }\end{array}$ & \\
\hline dmaW & $93 \%$ & Penicillium roqueforti & $\begin{array}{l}\text { Tryptophan } \\
\text { dimethylallyltransferase }\end{array}$ & CDM36678.1 \\
\hline easD & $99 \%$ & Aspergillus lentulus & $\begin{array}{l}\text { chanoclavine-I } \\
\text { dehydrogenase }\end{array}$ & GAQ03955.1
\end{tabular}



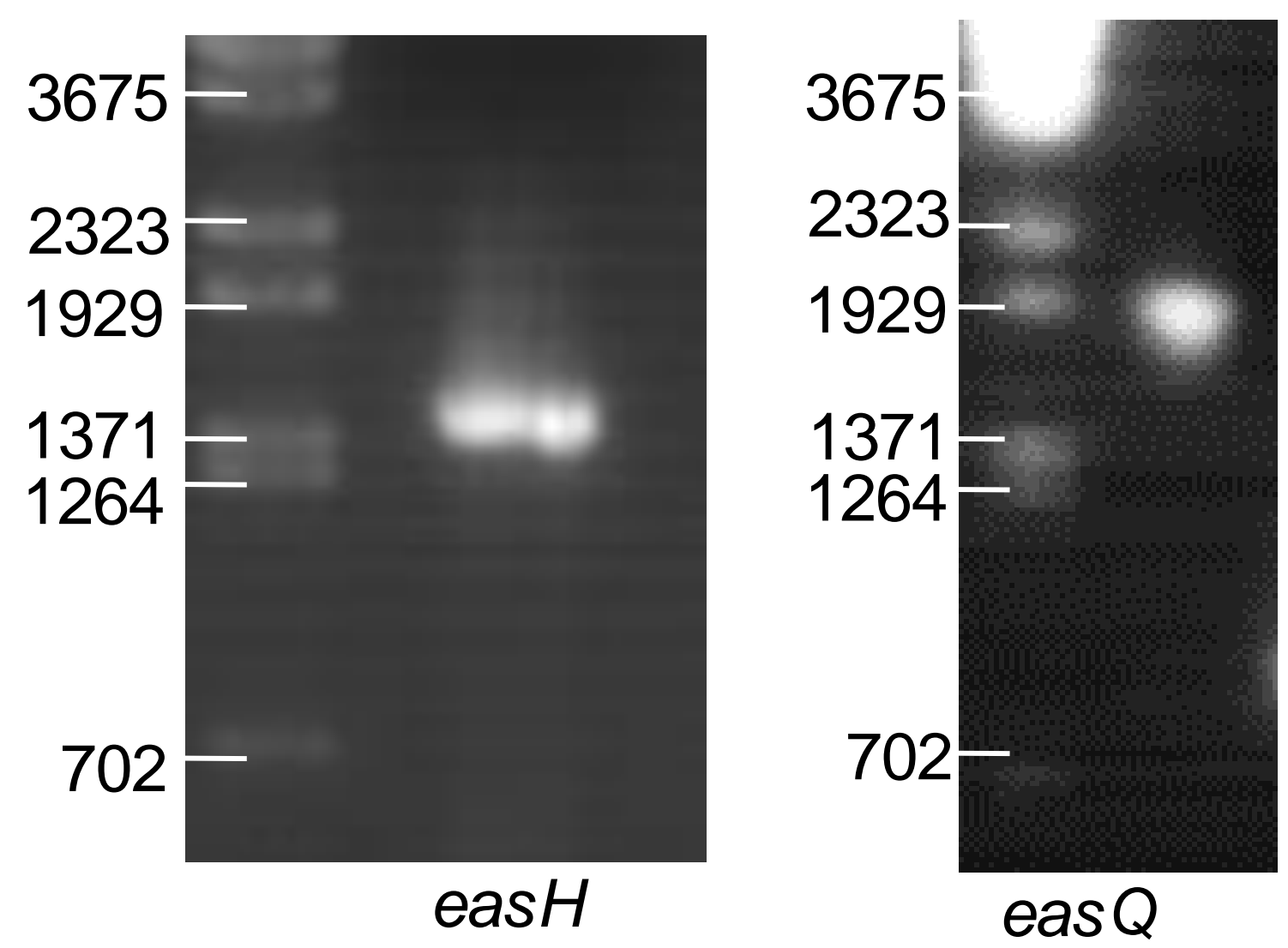

Figure 4: $P$. camemberti easH and eas $Q$ were both present in the transformed $N$. fumigata eas $A$ ko fungus. 


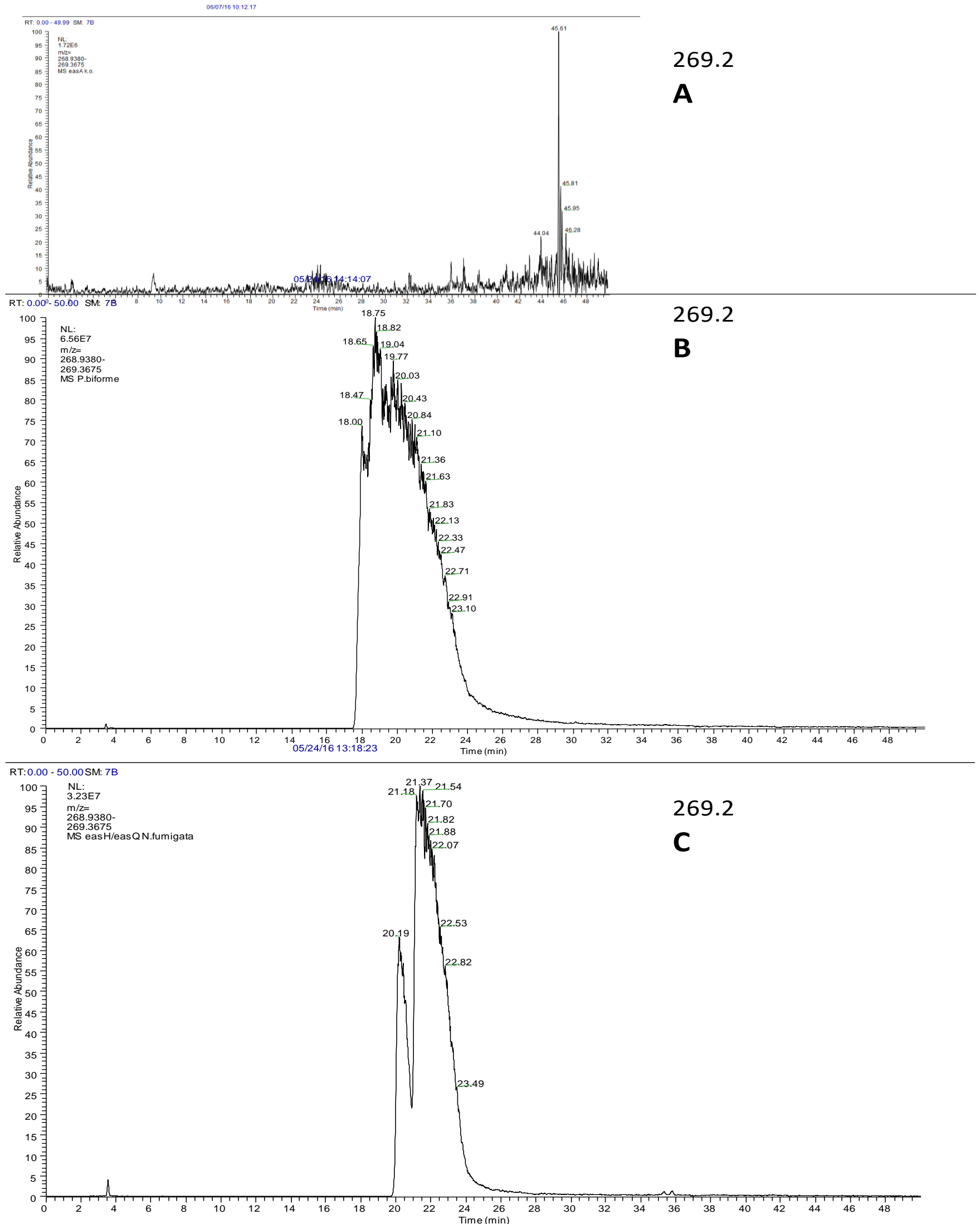

Figure 5. Extracted ion chromatogram m/z 269.2 from mass spectrometry analysis of $N$. fumigata eas $A$ ko $(\mathrm{A})$, the $N$. fumigata eas $A$ knockout transformed with eas $H$ and eas $Q(B)$, and $P$. biforme $(\mathrm{C})$. 


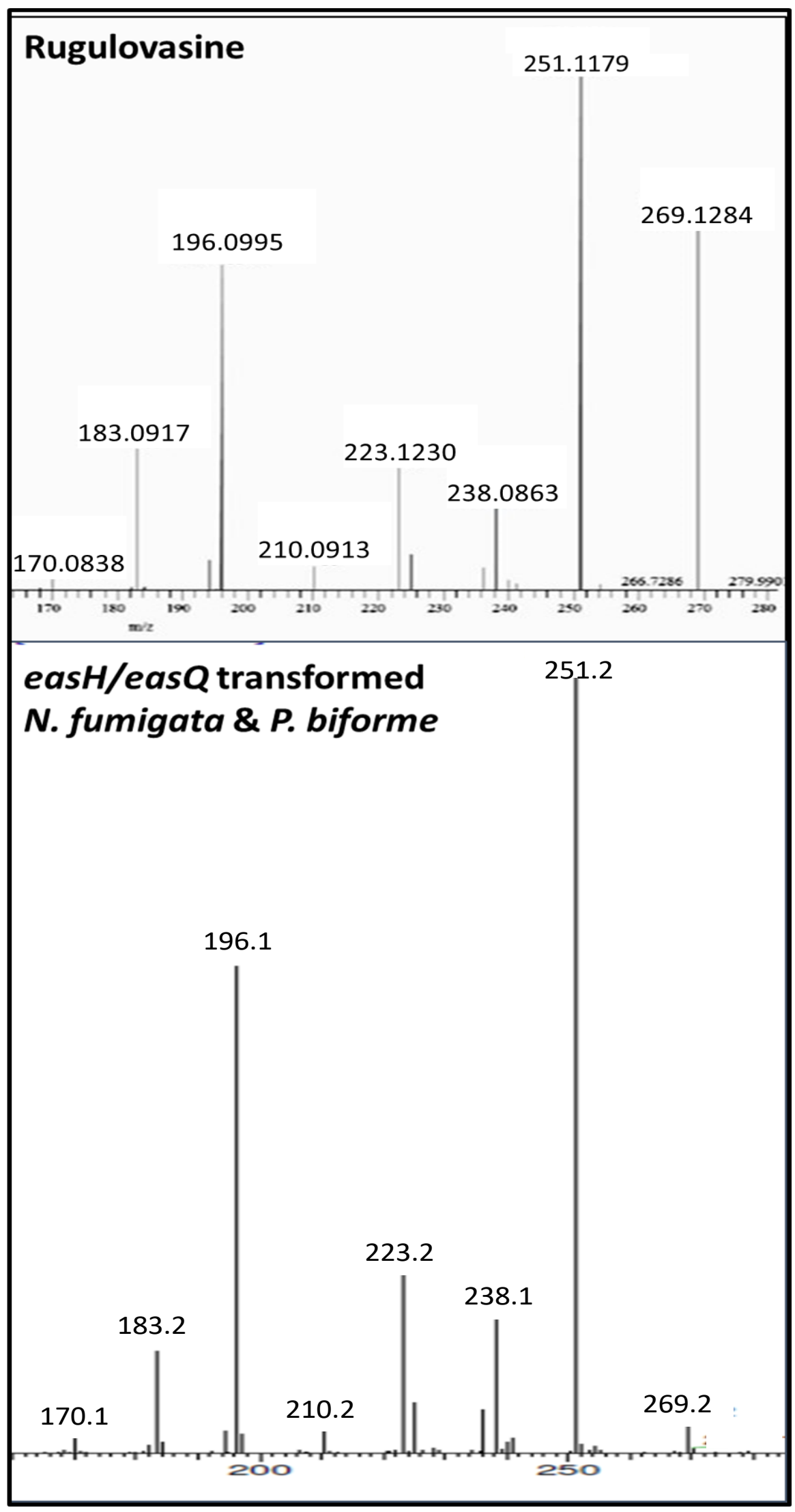

Figure 6: Mass spectrometry fragmentation patterns of rugulovasine (De Medeiros et. al., 2015) and the N. fumigata easA ko transformed with easH and easQ. 

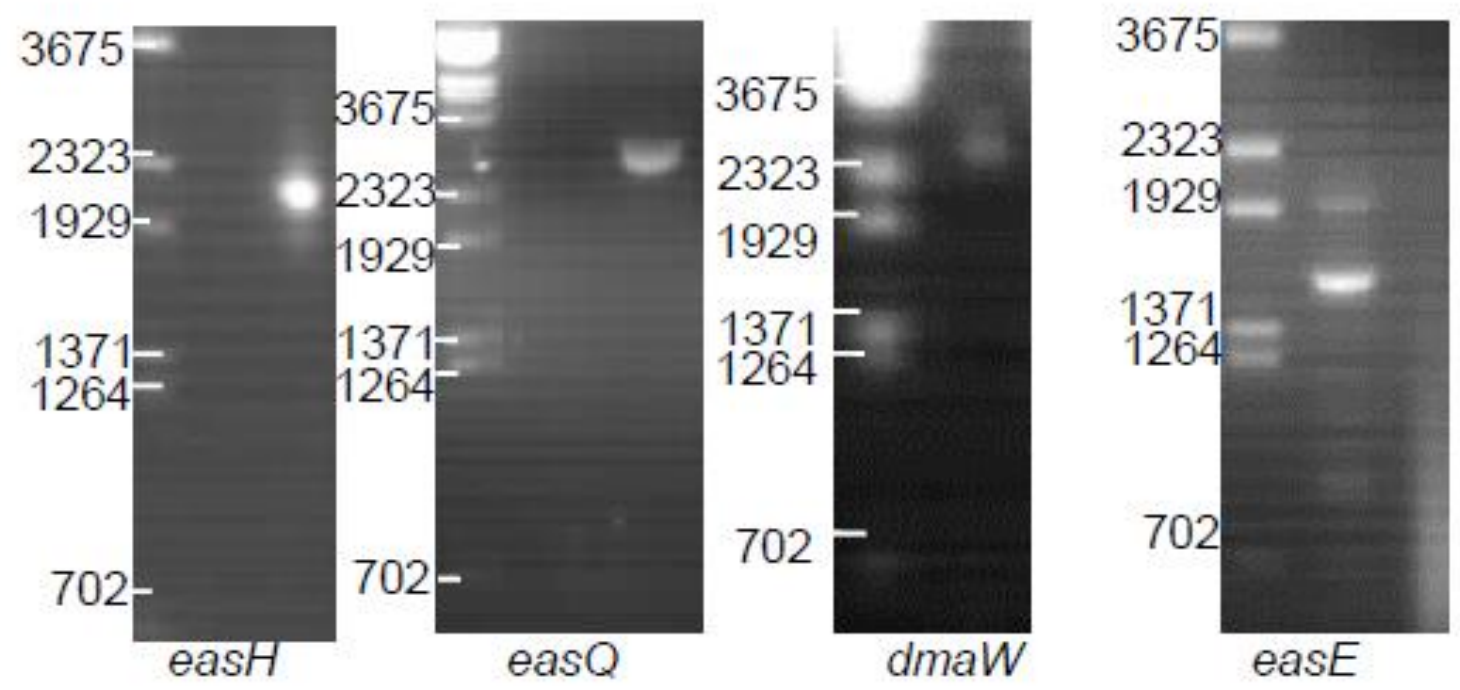

Figure 7: PCR evidence illustrating that fungal transformations were successful. Primer sets for specific amplification of the genes were used in conjunction with the transformed $N$. fumigata strains. A) presence of easH in the $N$. fumigata eas $A$ ko strain. B) presence of eas $Q$ in the $N$. fumigata eas $A$ ko strain. C) presence of $d m a W$ in the $N$. fumigata $d m a W$ ko strain. D) presence of easE in the $N$. fumigata easE ko strain. 


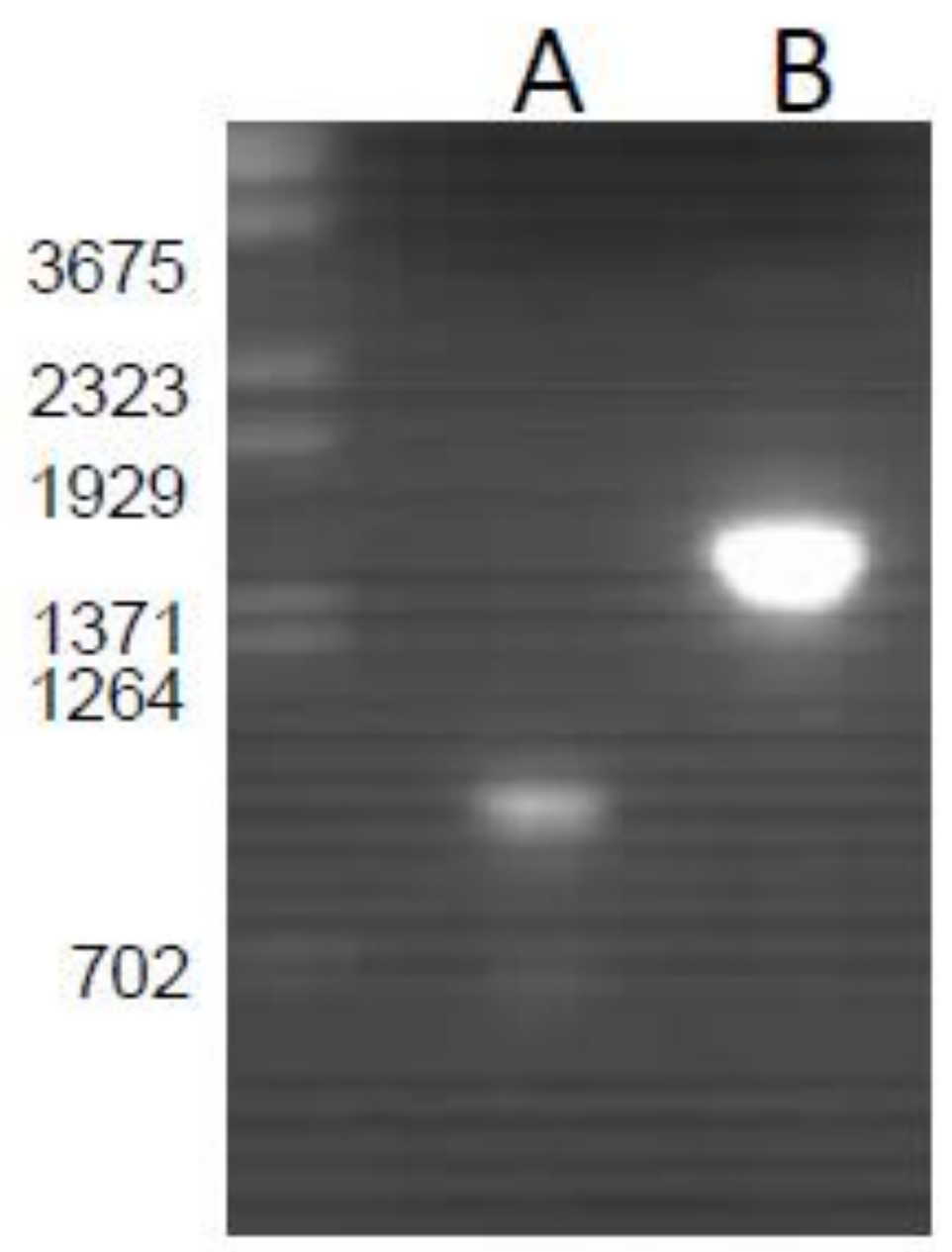

Figure 8: cDNA of the easH/easQ transformed $N$. fumigata easA knockout. A) shows presence of easH while B) shows eas $Q$. Primers for eas $Q$ flanked an intron, and the size (and DNA sequence) of the PCR product demonstrate it was derived from processed mRNA.. 


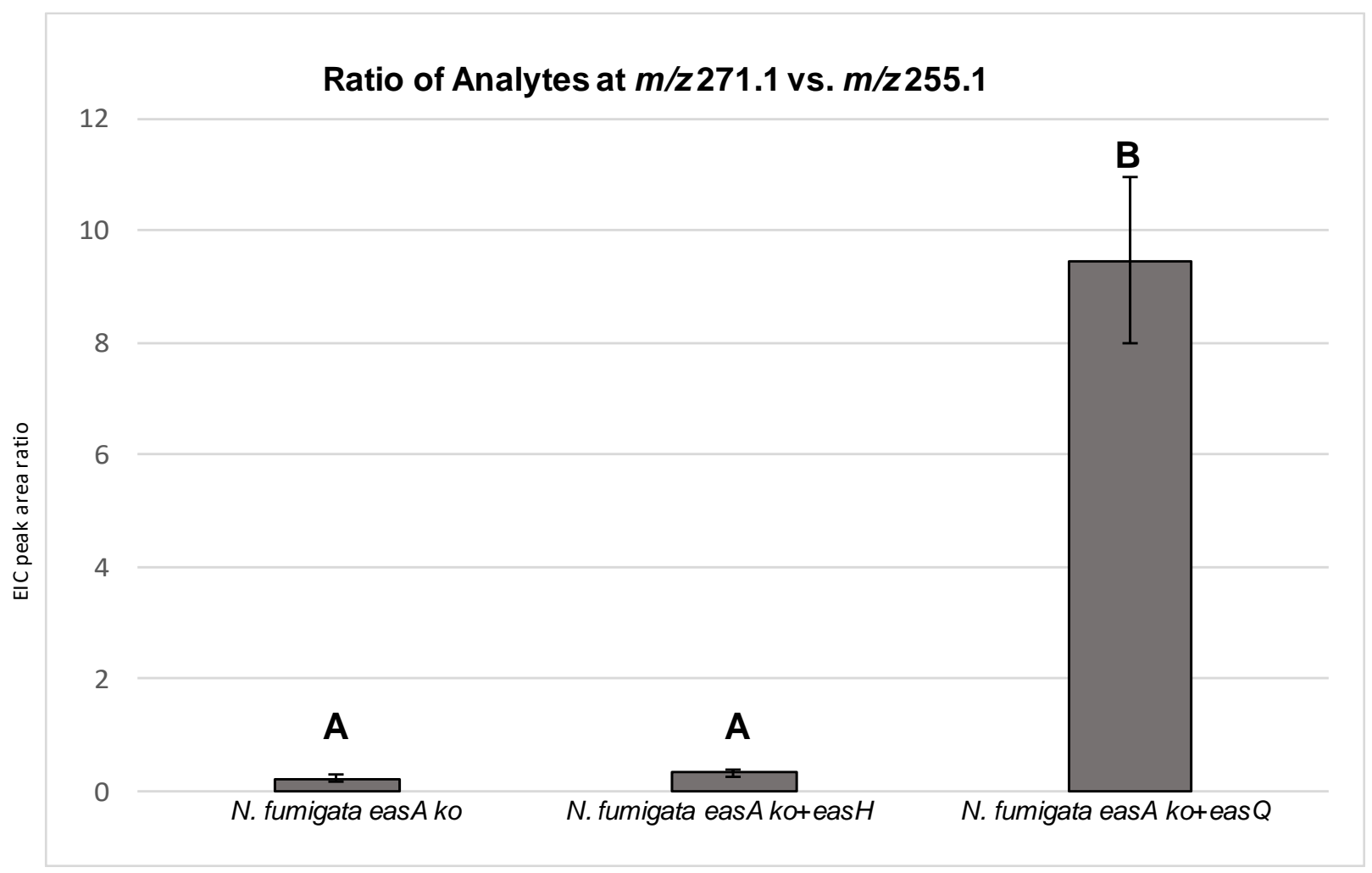

Figure 9: $271.1 / 255.1 \mathrm{~m} / \mathrm{z}$ ratio differences observed in the LC-MS data of $N$. fumigata eas $A$ ko, N. fumigata easA ko+easH and N. fumigata easA ko+eas Q. Brown-Forsythe analysis indicates significant differences between $A$ and $B$ as indicated by $p$-value further outlined in Table 3. 
Table 3: Calculated p-values by Brown-Forsythe analysis that show that there is a difference in ratio of $271.1 / 255.1 \mathrm{~m} / \mathrm{z}$ based on the strains analyzed. Asterisks indicate significance.

\begin{tabular}{l|l} 
Strains analyzed by LC-MS & $\mathbf{p}$-Value \\
\hline N. fumigata easA ko+ easQ vs. N. fumigata easA ko & $0.002^{*}$ \\
\hline N. fumigata easA ko+ easQ vs. N. fumigata easA ko+ easH & $0.007^{*}$ \\
\hline N. fumigata easA ko+ N. fumigata easA ko +easH & 0.673
\end{tabular}




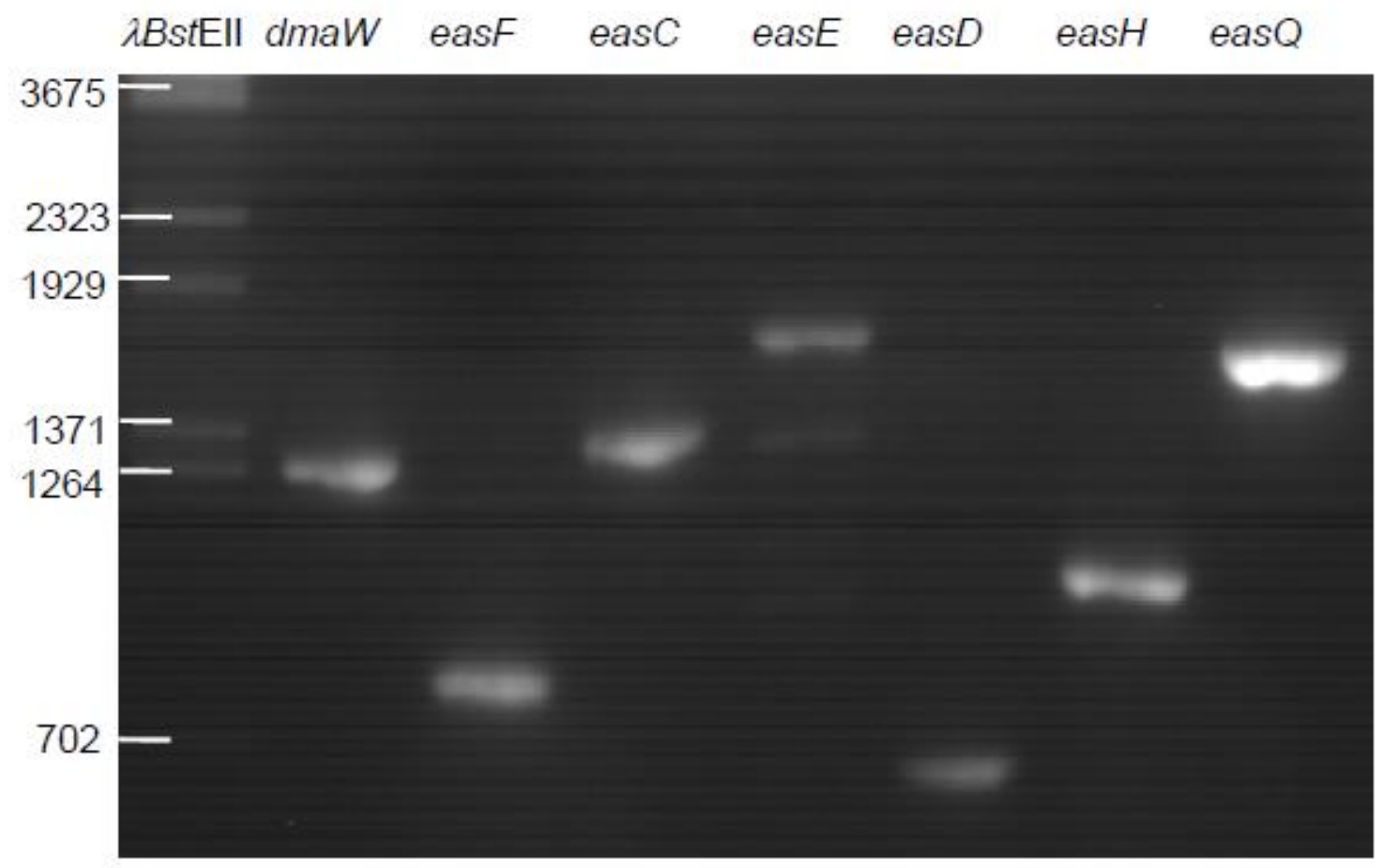

Figure 10: RT-PCR of dmaW, easF, eas $C$, easE, easD, eas $H$ and eas $Q$ transcripts from $P$. camemberti NRRL strain 874 cDNA. All seven genes in the ergot alkaloid gene cluster are being transcribed and expressed when the fungus was cultured in malt extract agar. 


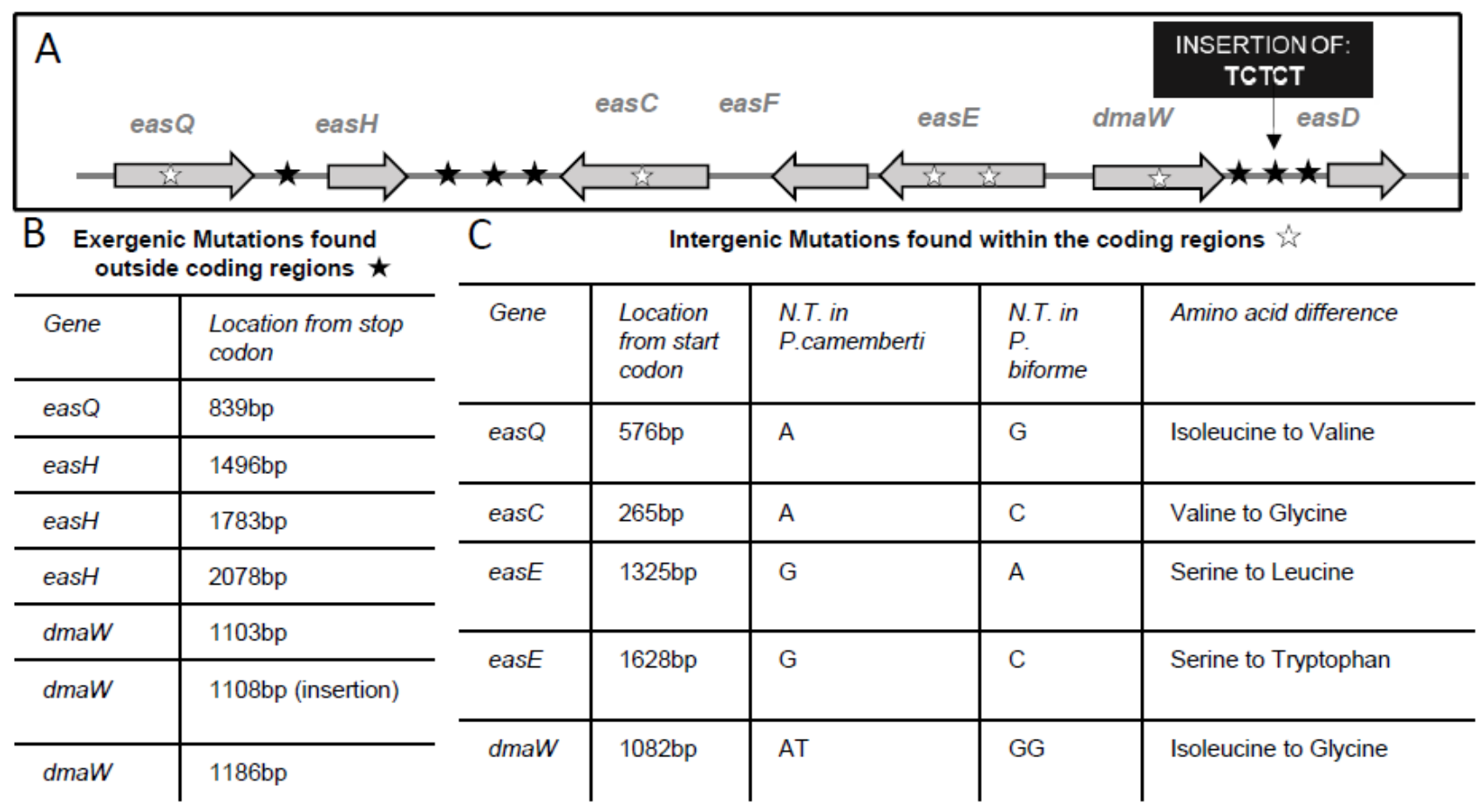

Figure 11: A) Mutation sites of the $P$. camemberti eas gene cluster in comparison to $P$. biforme as indicated with stars. Black stars indicate the mutations of the non coding region and are outlined in B), white stars indicate the mutations within the coding regions and are further outlined in C). 


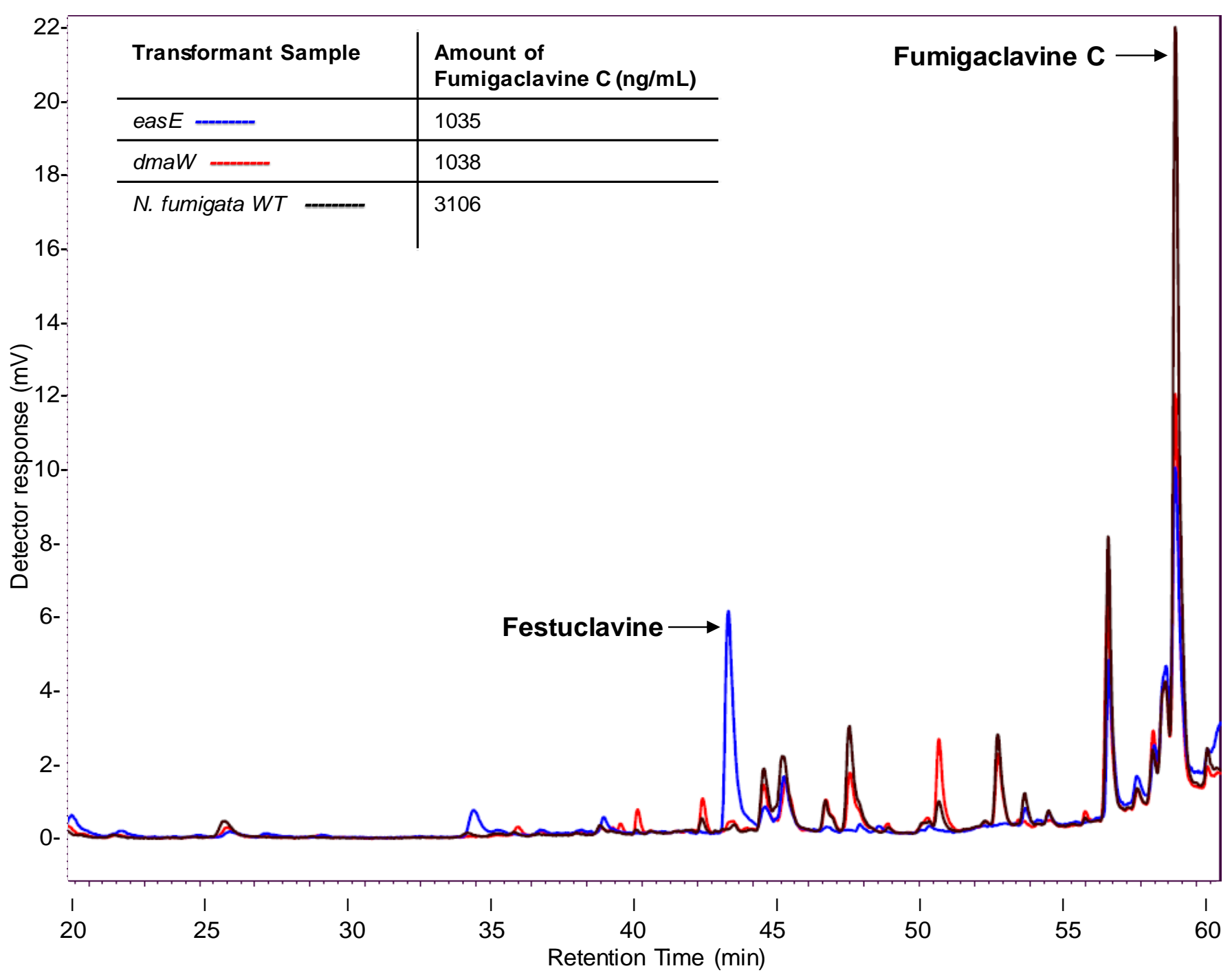

Figure 12: HPLC of the P. camemeberti easE (blue) and dmaW (red) N.fumigata knockout transformants in comparison to wild type N. fumigata (black). This analysis indicates that the two transformants are producing fumigaclavine $C$ (58.7), just in smaller quantities than the wild type $N$. fumigata. EasE transformant also appears to less efficient at converting festuclavine to fumigaclavine $\mathrm{C}$, thus the larger peak at 43.8 . 


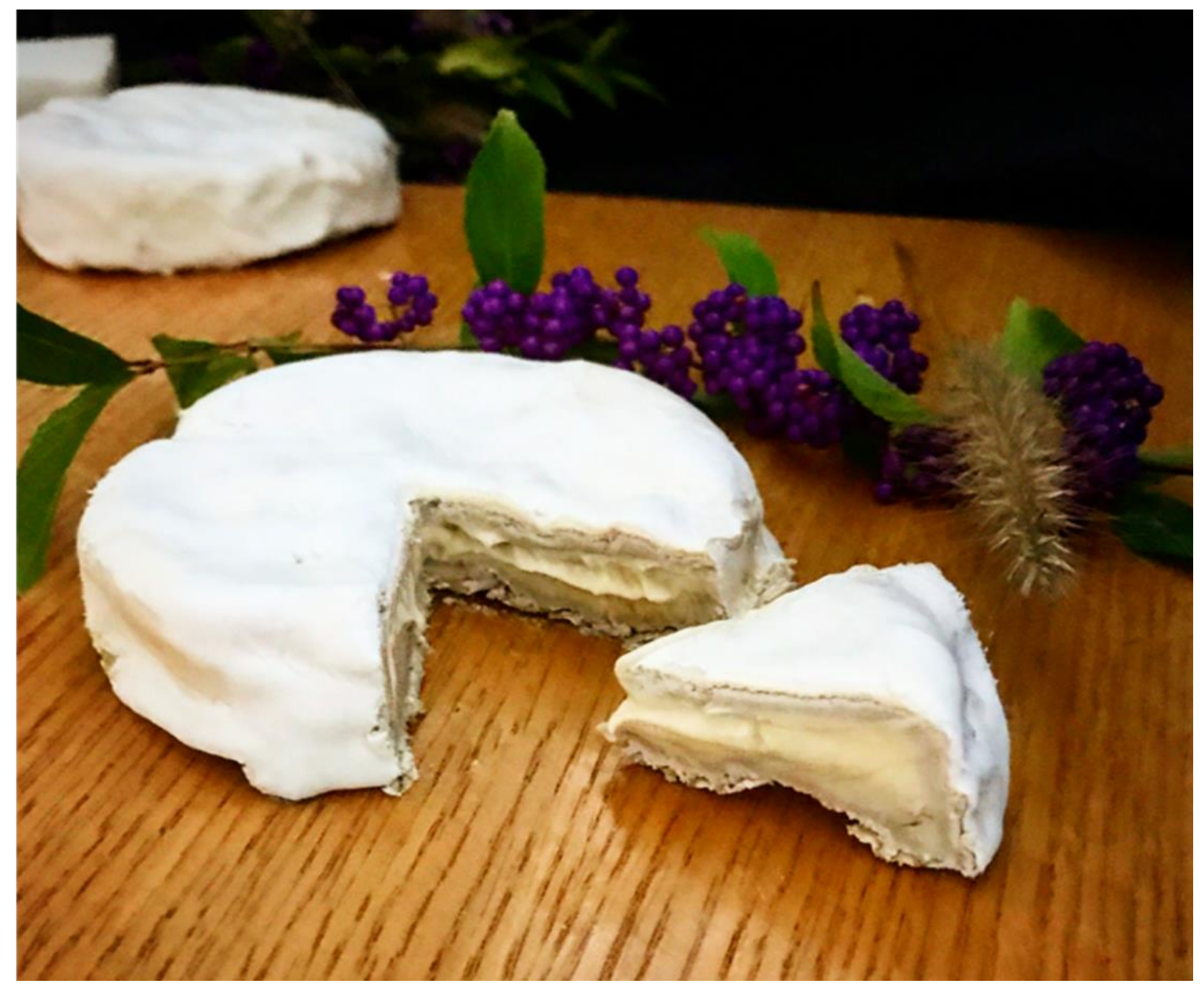

Figure 13: Camembert cheese prepared with $P$. camemberi NRRL 874 and $P$. biforme NRRL 885. These products were analyzed on the LC- MS for ergot alkaloids. 
A

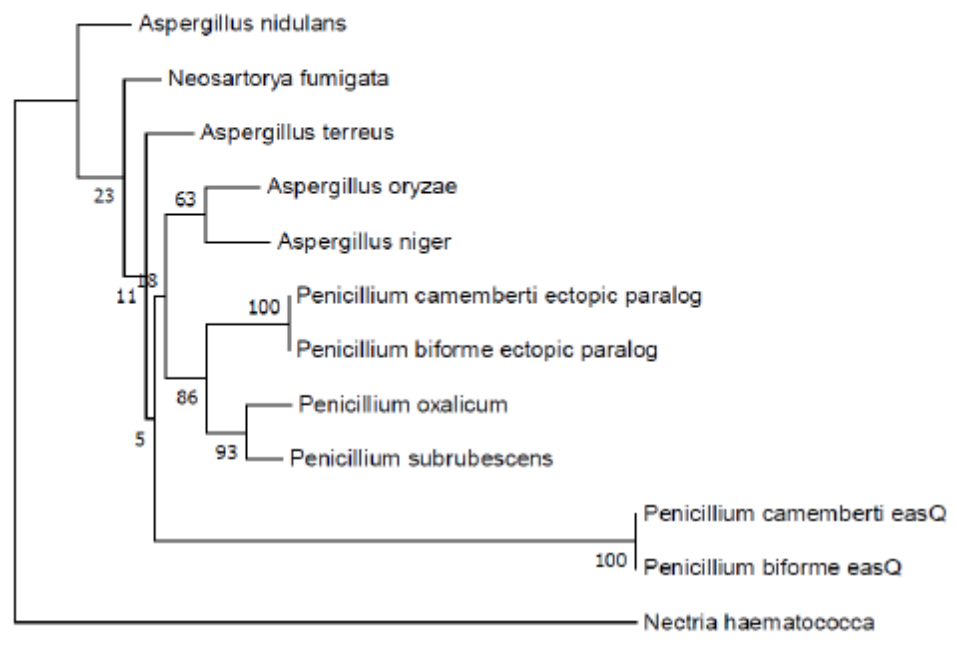

$\longmapsto$

B

\begin{tabular}{l|l|l} 
Species name & $\begin{array}{l}\text { Percent } \\
\text { identity }\end{array}$ & $\begin{array}{l}\text { E- } \\
\text { value }\end{array}$ \\
\hline Penicillium biforme & $100 \%$ & 0.0 \\
\hline Penicillium oxalicum & $66 \%$ & 0.0 \\
\hline Penicillium subrubescens & $66 \%$ & 0.0 \\
\hline Aspergillus niger & $66 \%$ & 0.0 \\
\hline Penicillium camemberti ectopic paralog & $58 \%$ & 0.0 \\
\hline Neosartorya fumigata & $65 \%$ & 0.0 \\
\hline Aspergillus terreus & $65 \%$ & 0.0 \\
\hline Aspergillus nidulans & $67 \%$ & 0.0 \\
\hline Penicillium biforme ectopic paralog & $66 \%$ & $1 \mathrm{e}-163$ \\
\hline Nectria haematococca & $60 \%$ & 0.0 \\
\hline
\end{tabular}

C
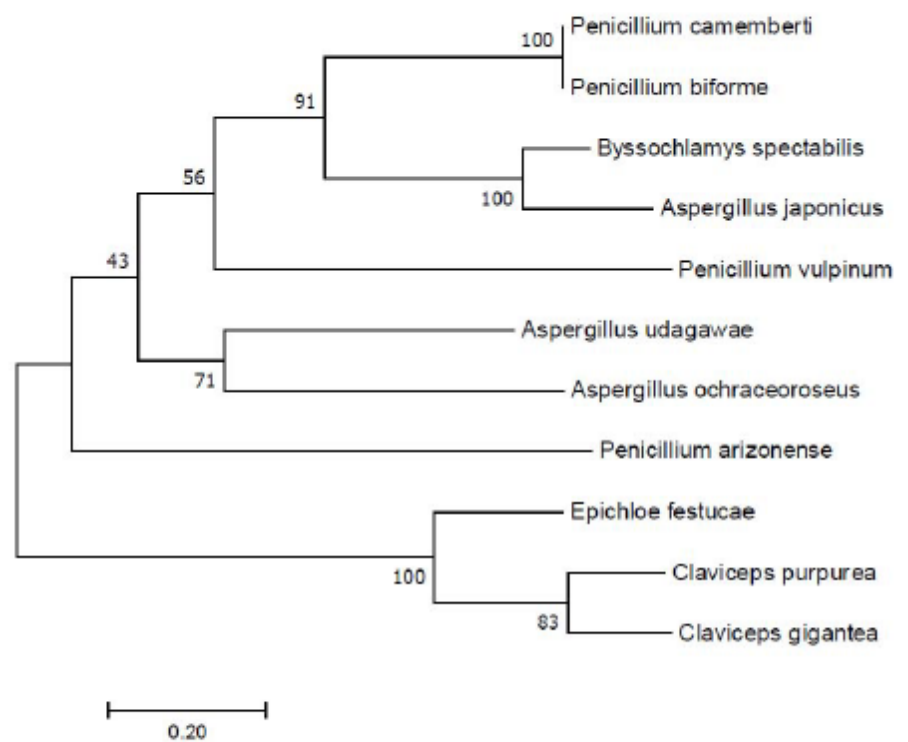

D

\begin{tabular}{l|l|l} 
Species name & $\begin{array}{l}\text { Percent } \\
\text { identity }\end{array}$ & E-value \\
\hline Penicillium biforme & $100 \%$ & 0.0 \\
\hline Byssochlamys spectabilis & $56 \%$ & $5 \mathrm{e}-123$ \\
\hline Aspergillus japonicus & $55 \%$ & $1 \mathrm{e}-114$ \\
\hline Aspergillus udagawae & $46 \%$ & $4 \mathrm{e}-86$ \\
\hline Penicillium vulpinum & $44 \%$ & $7 \mathrm{e}-79$ \\
\hline Aspergillus ochraceoroseus & $42 \%$ & $3 \mathrm{e}-75$ \\
\hline Penicillium arizonense & $42 \%$ & $6 \mathrm{e}-72$ \\
\hline Epichloe festucae & $35 \%$ & $2 \mathrm{e}-54$ \\
\hline Claviceps purpurea & $37 \%$ & $1 \mathrm{e}-50$ \\
\hline Claviceps gigantea & $40 \%$ & $9 \mathrm{e}-58$
\end{tabular}

Figure 14: Phylogenetic analysis of the eas $Q$ and easH genes from $P$. camemberti and their relationship to those of other fungi. A Phylogenetic relationship between the top NCBI blastp matches of the $P$. camemberti eas $Q$ gene. It is notable that there is a paralog of the $P$. camemberti and $P$. biforme eas $Q$ gene. B The numerical relationships between homologues of eas $Q$ from other fungi with eas $Q$ of $P$. camemberti. C Phylogenetic relationship of $P$. camemberti easH and homologues from other fungi. D Homologues of $P$. camemberti easH based on NCBI blastp search. It is interesting to note the close relationship between $P$. camemberti easH and Aspergillus japonicus eas $H$. 


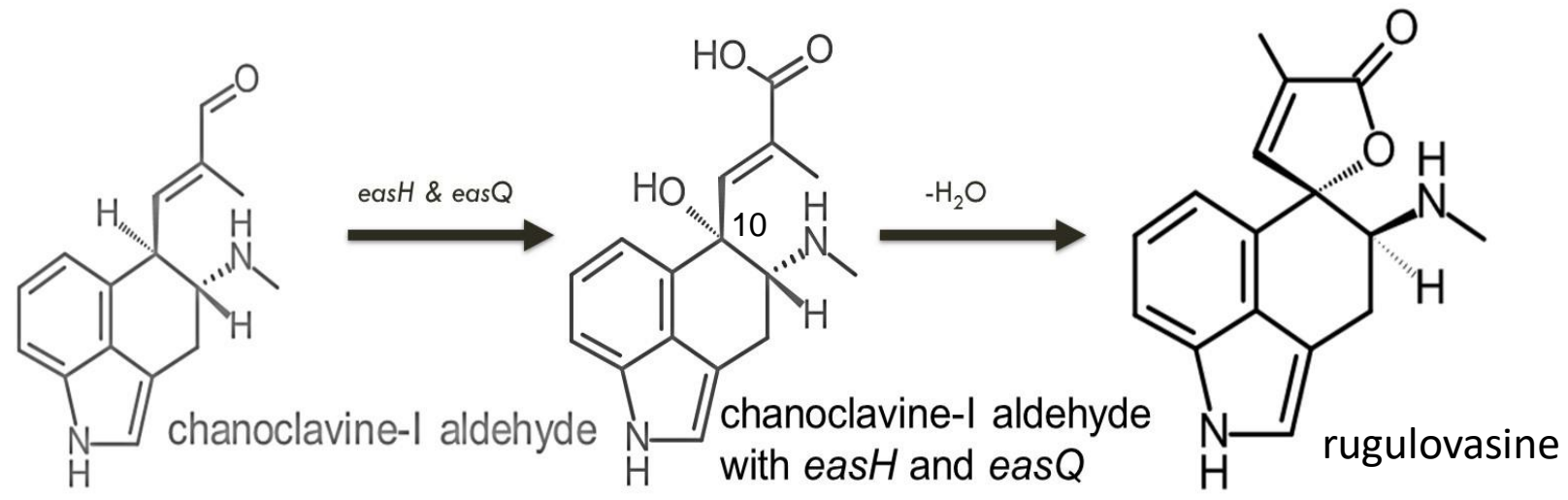

Figure 15: Proposed synthesis of rugulovasine from chanoclavine-l aldehyde. EasQ, predicted by sequence analysis to be an aldehyde dehydrogenase, would oxidize the aldehyde to an acid. $\mathrm{EasH}$, a predicted dioxygenase, would oxidize the aromatic carbon. Dehydration would result in the formation of rugulovasine. 

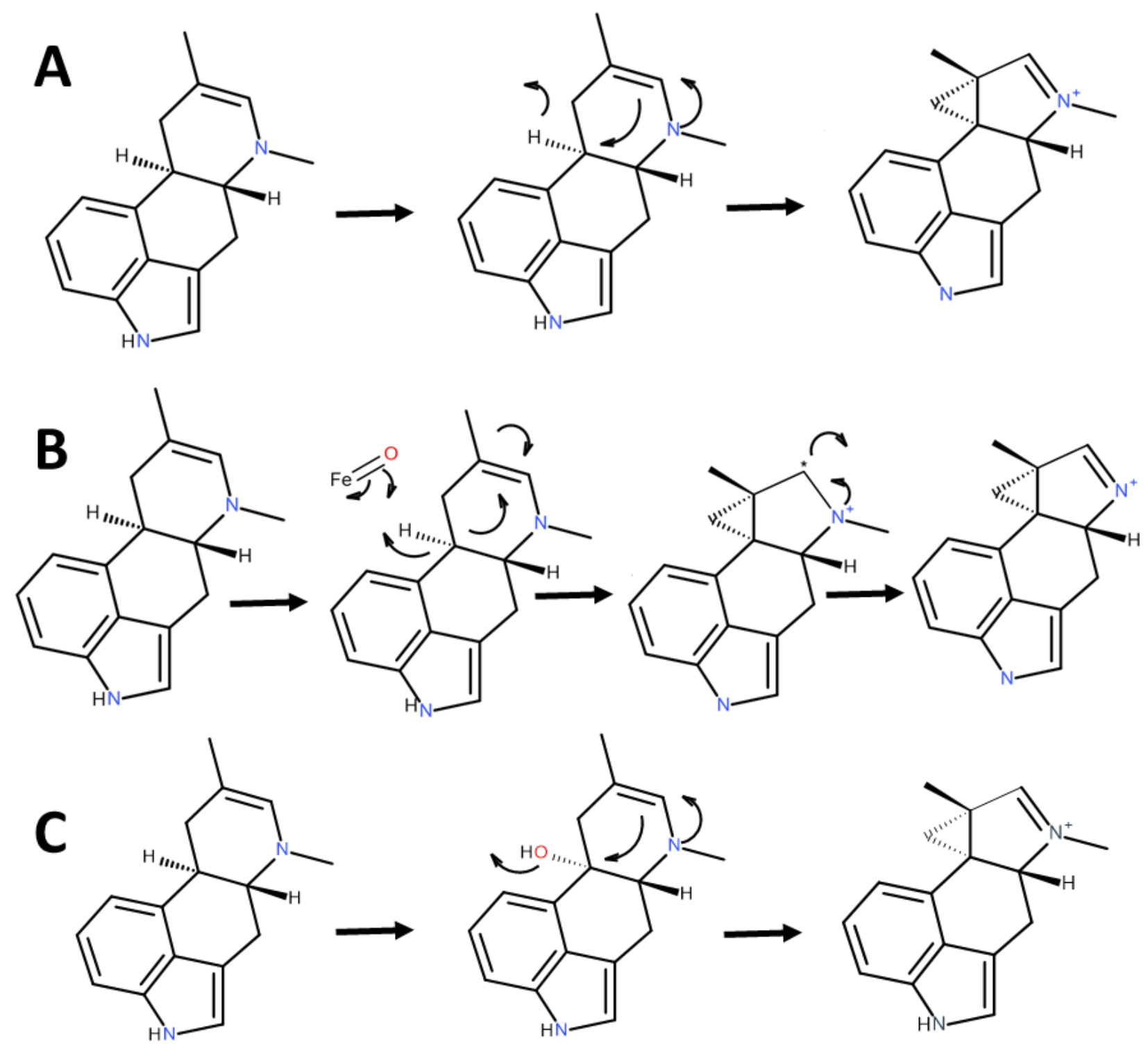

Figure 16: Proposed mechanisms of EasH activity as described by Jakubczyk et al. (2015) in the fungus Aspergillus japonicus. A EasH may be abstractring a hydride ion, $\mathrm{B}$ EasH may be abstracting a hydrogen ion from its substrate. $\mathbf{C}$ Eas $\mathrm{H}$ may be hydroxylating or halogenating its substrate. Hydroxylation is the mechanism that is consistent with our hypothesis for $P$. camemberti EasH activity. 


\section{Acknowledgements}

First I would like to thank my advisor, Dr. Daniel Panaccione for all your help throughout this project and for all the support and encouragement. Your patience and direction has been greatly appreciated. I would also like to thank my committee members Dr. Matt Kasson and Dr. Nik Kovinich for all of your guidance. Lastly, I would like to thank my family for their support and understanding throughout this journey.

\section{References}

Brakhage A, Schroeckh V. 2011. Fungal secondary metabolites-strategies to activate silent gene clusters. Fungal Genetics and Biology 48:15-22.

Cheeseman K, Ropars J, Renault P, Dupont J, Gouzy J, Branca A, Malagnac F. 2014. Multiple recent horizontal transfers of a large genomic region in cheese making fungi. Nature Communications 5:2876.

Coyle CM, Cheng JZ, O'Connor SE, Panaccione DG. 2010. An old yellow enzyme gene controls the branch point between Aspergillus fumigatus and Claviceps purpurea ergot alkaloid pathways. Applied and Environmental Microbiology 76:3898-903.

De Medeiros LS, da Silva JV, Abreu LM, Pfenning LH, Silva CL, Thomasi SS, Venâncio T, van Pée KH, Nielsen KF, Rodrigues-Filho E. 2015. Dichlorinated and brominated rugulovasines, ergot alkaloids produced by Talaromyces wortmannii. Molecules 20:17627-44.

Dorner JW, Cole RJ, Hill R, Wicklow D, Cox RH. 1980. Penicillium rubrum and Penicillium biforme, new sources of rugulovasines A and B. Applied and Environmental Microbiology 40:685-687.

Frisvad JC, Filtenborg O. 1989. Terverticillate penicillia: chemotaxonomy and mycotoxin production. Mycologia 1:837-61.

Giraud F, Giraud T, Aguileta G, Fournier E, Samson R, Cruaud C, Lacoste S, Ropars J, Tellier A, Dupont J. 2010. Microsatellite loci to recognize species for the cheese starter and contaminating strains associated with cheese manufacturing. International Journal of Food Microbiology 137:204-13.

Goetz KE, Coyle CM., Cheng JZ, O'Connor SE, Panaccione DG. 2011. Ergot clusterencoded catalase is required for synthesis of chanoclavine-I in Aspergillus fumigatus. Current Genetics 57:201-211. 
Gribble GW. 2008. Structure and biosynthesis of halogenated alkaloids. Modern Alkaloids: Structure, Isolation, Synthesis and Biology. Wiley 1:591-618.

Havemann J, Vogel D, Loll B, Keller U. 2014. Cyclolization of D-lysergic acid alkaloid peptides. Chemistry \& Biology 21:146-55.

Hulvová H, Galuszka P, Frébortová J, Frébort I. 2013. Parasitic fungus Claviceps as a source for biotechnological production of ergot alkaloids. Biotechnology Advances 31:79-89.

Jakubczyk D, Caputi L, Hatsch A, Nielsen CA, Diefenbacher M, Klein J, Molt A, Schröder H, Cheng JZ, Naesby M, O'Connor SE. 2015. Discovery and reconstitution of the cycloclavine biosynthetic pathway-Enzymatic formation of a cyclopropyl group. Angewandte Chemie International Edition 54:5117-21.

Keller N, Hohn T. 1997. Metabolic pathway gene clusters in filamentous fungi. Fungal Genetics Biology 21:17-29.

Kozlovsky AG. 1999. Producers of ergot alkaloids out of claviceps genus. ergot: the genus Claviceps. The Gordon and Breach Publishing Group 1:479-98.

Larsen AG, Knöchel S. 1997. Antimicrobial activity of food-related Penicillium sp. against pathogenic bacteria in laboratory media and a cheese model system. Journal of applied microbiology 83:111-119.

Lorenz N, Olšovská J, Šulc M, Tudzynski P. 2010. Alkaloid cluster gene ccsA of the ergot fungus Claviceps purpurea encodes chanoclavine I synthase, a flavin adenine dinucleotide-containing oxidoreductase mediating the transformation of $\mathrm{N}$-methyldimethylallyltryptophan to chanoclavine I. Applied and environmental microbiology 76:1822-1830.

Lindahl R. 1992. Aldehyde dehydrogenases and their role in carcinogenesis. Critical Reviews in Biochemistry and Molecular Biology 27:283-335.

Martín JF, Álvarez-Álvarez R, Liras P. 2017. Clavine alkaloids gene clusters of penicillium and related fungi: evolutionary combination of prenyltransferases, monooxygenases and dioxygenases. Genes 8:1-19.

McSweeney P. 2004. Biochemistry of cheese ripening. International Journal of Dairy Technology 57:127-144.

McSweeney PL, Fox PF. 2004. Metabolism of residual lactose and of lactate and citrate. Cheese: Chemistry, Physics and Microbiology 1:361-371.

Meurant G. 2012. Handbook of toxic fungal metabolites. Elsevier 1:528-44.

Nielsen KF, Sumarah MW, Frisvad JC, Miller JD. 2006. Production of metabolites from the Penicillium roqueforti complex. Journal of Agricultural and Food Chemistry 54:37563763.

Panaccione DG. 2005. Origins and significance of ergot alkaloid diversity in fungi. FEMS Microbiology Letters 251:9-17. 
Panaccione DG, Coyle CM. 2005. Abundant respirable ergot alkaloids from the common airborne fungus Aspergillus fumigatus. Applied Environmental Microbiology 71:3106-111.

Panaccione DG, Ryan KL, Schardl CL, Florea S. 2012. Analysis and modification of ergot alkaloid profiles in fungi. Methods in Enzymology 515:267-90.

Polonelli L, Morace G, Rosa R, Castagnola MA, Frisvad JC.1987. Antigenic characterization of Penicillium camemberti and related common cheese contaminants. Applied and Environmental Microbiology 53:872-8.

Rigbers O, Li SM. 2008. Ergot alkaloid biosynthesis in Aspergillus fumigatus overproduction and biochemical characterization of a 4-dimethylallyltryptophan $\mathrm{N}$ methyltransferase. Journal of Biological Chemistry 283: 26859-26868.

Robinson SL, Panaccione DG. 2015. Diversification of ergot alkaloids in natural and modified fungi. Toxins 7:201-18.

Ropars J, De la Vega RCR, López-Villavicencio M, Gouzy J, Sallet E, Dumas É, Giraud T. 2015. Adaptive horizontal gene transfers between multiple cheese-associated fungi. Current Biology 25:2562-2569.

Ryan KL, Moore CT, Panaccione DG. 2013. Partial reconstruction of the ergot alkaloid pathway by heterologous gene expression in Aspergillus nidulans. Toxins 5:445-55.

Rykard DM, Luttrell ES, Bacon CW.1982. Development of the conidial state of Myriogenospora atramentosa. Mycologia 74:648-54.

Schardl CL, Panaccione DG, Tudzynski P. 2006. Ergot alkaloids-biology and molecular biology. The alkaloids: chemistry and biology. Elsevier 63:45-86.

Spinnler HE, Gripon JC. 2004. Surface mould-ripened cheeses. Cheese: Chemistry, physics and microbiology. Elsevier 2:157-174.

Tudzynski P, Correia T, Keller U. 2001. Biotechnology and genetics of ergot alkaloids. Applied Microbiology and Biotechnology 57:593-605.

VanDongen PW, DeGroot AN. 1995. History of ergot alkaloids from ergotism to ergometrine. European Journal of Obstetrics \& Gynecology and Reproductive Biology 60:109-116.

Wang J, Machado C, Panaccione DG, Tsai HF, Schardl CL. 2004. The determinant step in ergot alkaloid biosynthesis by an endophyte of perennial ryegrass. Fungal Genetics and Biology 41:189-198.

Wallwey C, Li S-M. 2011. Ergot alkaloids: structure diversity, biosynthetic gene clusters and functional proof of biosynthetic genes. Nat. Prod. Rep. 28:496-510.

Zhang YA, Liu Q, Wang C, Jia Y. 2013. Total Synthesis of Rugulovasine A. Organic letters 15:3662-5 
